\title{
Drug-Induced Alterations of Mitochondrial DNA Homeostasis in Steatotic and Nonsteatotic HepaRG Cells
}

\author{
Dounia Le Guillou, Simon Bucher, Karima Begriche, Delphine Hoët, Anne Lombès, \\ Gilles Labbe, and Bernard Fromenty \\ INSERM, INRA, Université de Rennes, UBL, Nutrition Metabolisms and Cancer (NuMeCan), Rennes, France (D.L.G., S.B., K.B., \\ B.F.); Sanofi, Investigative Toxicology, Alfortville, France (D.H., G.L.); and INSERM, UMR 1016, Institut Cochin, Université Paris V \\ René Descartes, Paris, France (A.L.)
}

Received November 29, 2017; accepted April 6, 2018

\begin{abstract}
Although mitochondriotoxicity plays a major role in druginduced hepatotoxicity, alteration of mitochondrial DNA (mtDNA) homeostasis has been described only with a few drugs. Because it requires long drug exposure, this mechanism of toxicity cannot be detected with investigations performed in isolated liver mitochondria or cultured cells exposed to drugs for several hours or a few days. Thus, a first aim of this study was to determine whether a 2-week treatment with nine hepatotoxic drugs could affect mtDNA homeostasis in HepaRG cells. Previous investigations with these drugs showed rapid toxicity on oxidative phosphorylation but did not address the possibility of delayed toxicity secondary to mtDNA homeostasis impairment. The maximal concentration used for each drug induced about $10 \%$ cytotoxicity. Two other drugs, zalcitabine and linezolid, were used as positive controls for their respective effects on mtDNA replication and translation. Another goal was
\end{abstract}

to determine whether drug-induced mitochondriotoxicity could be modulated by lipid overload mimicking nonalcoholic fatty liver. Among the nine drugs, imipramine and ritonavir induced mitochondrial effects suggesting alteration of mtDNA translation. Ritonavir toxicity was stronger in nonsteatotic cells. None of the nine drugs decreased mtDNA levels. However, increased mtDNA was observed with five drugs, especially in nonsteatotic cells. The mtDNA levels could not be correlated with the expression of key factors involved in mitochondrial biogenesis, such as peroxisome proliferator-activated receptor- $\gamma$ coactivator $1 \alpha(\mathrm{PGC} 1 \alpha), \mathrm{PGC} 1 \beta$, and AMP-activated protein kinase $\alpha$-subunit. Hence, drug-induced impairment of mtDNA translation might not be rare, and increased mtDNA levels could be a frequent adaptive response to slight energy shortage. Nevertheless, this adaptation could be impaired by lipid overload.

\section{Introduction}

Although mitochondrial dysfunction is deemed to be a major mechanism of drug-induced liver injury (Begriche et al., 2011; Will and Dykens, 2014), alteration of mitochondrial DNA (mtDNA) homeostasis has been described so far only with a few drugs (Cohen, 2010; Schon and Fromenty, 2015). For instance, the antiretroviral nucleoside reverse transcriptase inhibitors (NRTIs) zalcitabine (ddC), stavudine, and

This work was supported by Sanofi (including stipend to D.L.G.). S.B. was recipient of a fellowship from the Région Bretagne and the Agence Nationale de la Recherche (STEATOX project; "ANR-13-CESA-0009”). B.F. received personal fees from Alfasigma France and Novo Nordisk outside the submitted work.

https://doi.org/10.1124/jpet.117.246751. zidovudine are able to block mtDNA replication via an inhibition of the DNA polymerase $\gamma$, thus inducing a progressive reduction of mtDNA levels in liver (Walker et al., 2004; Schon and Fromenty, 2015). The antibiotics linezolid (LNZ) and tetracycline can specifically impair mtDNA translation, possibly by interacting with the mitochondrial ribosomes (De Vriese et al., 2006; Moullan et al., 2015).

Because mtDNA encodes for 13 oxidative phosphorylation (OXPHOS) polypeptides, any significant alteration of mtDNA replication, transcription, or translation can cause energy shortage and severe liver diseases (Wallace et al., 2010; Schon and Fromenty, 2015). However, because there is an excess of mtDNA copies in most cells, OXPHOS will be impaired only after severe decrease of the mtDNA content (Schon and Fromenty, 2015). It has been determined that the number of

ABBREVIATIONS: A-769662, 4-hydroxy-3-[4-(2-hydroxyphenyl)phenyl]-6-oxo-7H-thieno[2,3-b]pyridine-5-carbonitrile); AMPK $\alpha$, AMP-activated protein kinase $\alpha$-subunit; ANOVA, analysis of variance; APOA4, apolipoprotein A4; COX2, cytochrome $c$ oxidase subunit 2 (protein); COX4, cytochrome $c$ oxidase subunit 4 (protein); COX4l1, cytochrome $c$ oxidase subunit 4 (gene); CPT, carnitine palmitoyltransferase; CS, citrate synthase; CYP, cytochrome P450 enzyme; ddC, zalcitabine; DMSO, dimethylsulfoxide; FAO, fatty acid oxidation; FBS, fetal bovine serum; FCCP, carbonyl cyanide $p$-trifluoromethoxyphenylhydrazone; $\mathrm{IC}_{10}$, $10 \%$ inhibitory concentration; $\mathrm{LNZ}$, linezolid; MT-CO2, cytochrome $c$ oxidase subunit 2 (gene); mtDNA, mitochondrial DNA; MT-ND1, NADH dehydrogenase subunit 1 (gene); NAFLD, nonalcoholic fatty liver disease; ND1, NADH dehydrogenase subunit 1 (protein); nDNA, nuclear DNA; NRF, nuclear respiratory factor; NRTI, nucleoside reverse transcriptase inhibitor; OXPHOS, oxidative phosphorylation; PBS, phosphate-buffered saline; PGC-1, peroxisome proliferator-activated receptor- $\gamma$ coactivator 1; PHH, primary human hepatocytes; PI, protease inhibitor; PLIN, perilipin; POLG, DNA polymerase $\gamma$; POLRMT, mitochondrial RNA polymerase; RT-qPCR, realtime quantitative polymerase chain reaction; TFAM, mitochondrial transcription factor $A$. 
mtDNA copies must fall below $20 \%-40 \%$ of basal levels to induce a significant mitochondrial dysfunction (Igoudjil et al., 2006; Begriche et al., 2011). Importantly, other threshold effects exist in mitochondria including at the levels of mitochondrial protein synthesis and OXPHOS activity (Rossignol et al., 1999, 2003). These different thresholds explain why mitochondrial toxicity and liver injury induced by NRTIs and LNZ can occur in patients after several weeks or months of treatment (Spengler et al., 2002; Walker et al., 2004; De Vriese et al., 2006; De Bus et al., 2010).

Currently, most in vitro investigations addressing druginduced mitochondrial toxicity are performed in isolated liver mitochondria (Porceddu et al., 2012; Marroquin et al., 2014) and in cultured cells exposed to the tested drugs for several hours or a few days at most (Kamalian et al., 2015; Eakins et al., 2016). These investigations can detect direct and rapid impairment of OXPHOS and the fatty acid oxidation (FAO) pathway but not mitochondrial dysfunction secondary to alterations of mtDNA homeostasis.

Hence, a first aim of this study was to investigate, in the metabolically competent human hepatoma HepaRG cell line, the effects of 11 hepatotoxic drugs on mtDNA homeostasis after 2 weeks of treatment, namely LNZ, ddC, amiodarone, atorvastatin, carbamazepine, imipramine, lovastatin, perhexiline, ritonavir, terbinafine, and troglitazone. The drugs ddC and LNZ were selected as model molecules to ascertain whether HepaRG cells could be used as a valuable model to detect drug-induced inhibition of mtDNA replication and translation, respectively (Walker et al., 2004; De Vriese et al., 2006; Schon and Fromenty, 2015). The other drugs were chosen because previous studies in isolated liver mitochondria showed that they directly impaired OXPHOS at relatively low concentrations (Fromenty et al., 1990; Deschamps et al., 1994; Porceddu et al., 2012), but those investigations did not address the possibility that their hepatotoxicity might also be mediated by a deleterious effect on mtDNA homeostasis.

The second aim of this study was to compare the long-term cytotoxicity and mitochondriotoxicity of these drugs between nonsteatotic and steatotic HepaRG cells. Indeed, some drugs such as acetaminophen, halothane, and methotrexate are more hepatotoxic in the context of obesity and associated nonalcoholic fatty liver disease (NAFLD) (Fromenty, 2013; Michaut et al., 2014; Massart et al., 2017). Although the mechanisms of this increased susceptibility are not precisely known, higher formation of cytochrome P450-generated toxic metabolites and preexistent mitochondrial dysfunction could be involved, at least for some pharmaceuticals (Fromenty, 2013; Massart et al., 2017). Because obesity and NAFLD are highly prevalent in numerous countries, it is important to determine which drugs could present a higher risk of hepatotoxicity in obese patients.

\section{Materials and Methods}

Chemicals and Reagents. Amiodarone, atorvastatin, carbamazepine, imipramine, lovastatin, perhexiline, ritonavir, terbinafine, troglitazone, ddC, LNZ, testosterone, $6 \beta$-hydroxytestosterone, chlorzoxazone (CZX), dimethylsulfoxide (DMSO), D-(+)-galactose, oleic acid, stearic acid, and insulin were purchased from Sigma-Aldrich (Saint-Quentin-Fallavier, France). [U- $\left.{ }^{14} \mathrm{C}\right]$-palmitic acid was supplied by PerkinElmer (Waltham, MA). A-769662 (4-hydroxy-3-[4-(2-
hydroxyphenyl)phenyl]-6-oxo-7H-thieno[2,3-b]pyridine-5-carbonitrile) was purchased from Santa Cruz Biotechnology (Dallas, TX). Williams' E medium, glutamine, penicillin/streptomycin, Nile red, and Hoechst dyes were obtained from Thermo Fisher Scientific (Waltham, MA). Williams' E medium without glucose was supplied by CliniSciences (Nanterre, France). Fetal bovine serum (FBS) was supplied by Lonza (Levallois-Perret, France). Hydrocortisone hemisuccinate was purchased from SERB Laboratories (Paris, France). Protease and phosphatase inhibitors were supplied by Roche Diagnostics (Indianapolis, IN).

Cell Cultures and Treatments. Native HepaRG cells were cultured as previously described elsewhere (Michaut et al., 2016). Briefly, HepaRG cells were seeded at a density of $2.6 \times 10^{4}$ cells $/ \mathrm{cm}^{2}$ and were first incubated in a Williams' $E$ medium supplemented with $10 \% \mathrm{FBS}, 100 \mathrm{U} / \mathrm{ml}$ penicillin, $100 \mu \mathrm{g} / \mathrm{ml}$ streptomycin, $2 \mathrm{mM}$ glutamine, $5 \mu \mathrm{g} / \mathrm{ml}$ insulin, and $50 \mu \mathrm{M}$ hydrocortisone hemisuccinate. After 2 weeks, cell differentiation was induced by culturing the HepaRG cells in the same medium supplemented with $2 \%$ DMSO for two additional weeks. The cells were then maintained for two additional weeks in the same culture medium except for the FBS and DMSO concentrations that were set at $5 \%$ and $1 \%$, respectively.

To induce steatosis, HepaRG cells were treated during this 2 week-period with a mixture of stearic acid $(150 \mu \mathrm{M})$ and oleic acid $(150 \mu \mathrm{M})$. For drug treatments, nonsteatotic and steatotic HepaRG cells were incubated during the same period with each compound at different concentrations. In some experiments, the cells were treated with $30 \mu \mathrm{M}$ of A-769662, a direct activator of AMP-activated protein kinase $\alpha$-subunit (AMPK $\alpha$ ). Stearic acid, oleic acid, and the different drugs were dissolved in DMSO whose final concentration in the cultures was always maintained at $1 \%$. Whatever the treatments including A-769662, the culture medium was renewed every 2 or 3 days during the 2 -week experiments. To this end, newly added medium contained each selected drug (or no drug) with or without the fatty acid mixture.

For some investigations with LNZ, ddC, imipramine, and ritonavir, HepaRG cells were treated for 3 days with two treatments over this time period. All investigations were performed 24 hours after the last drug treatment, except for AMPK $\alpha$ activation which was assessed 6 hours after the last drug treatment. HepaRG cells were used at passages 11-15.

Primary human hepatocytes (PHH) were obtained from Biopredic International (Saint-Grégoire, France). Briefly, $\mathrm{PHH}$ were isolated by collagenase perfusion of peritumoral liver tissue from four male adult donors who underwent resection for hepatic metastases. PHH were then seeded at a density of $0.2 \times 10^{5}$ cells $/ \mathrm{cm}^{2}$ onto rat collagen I-coated plates in a medium provided by Biopredic International. This medium was discarded 12 hours after cell seeding and the $\mathrm{PHH}$ cultures were maintained for 24 hours in Williams' $\mathrm{E}$ medium supplemented with $10 \%$ FBS, 2\% DMSO, $100 \mathrm{U} / \mathrm{ml}$ penicillin, $100 \mu \mathrm{g} / \mathrm{ml}$ streptomycin, $2 \mathrm{mM}$ glutamine, $5 \mu \mathrm{g} / \mathrm{ml}$ insulin, and $50 \mu \mathrm{M}$ hydrocortisone hemisuccinate. The $\mathrm{PHH}$ were then maintained for 12 days in the same culture medium except for the FBS and DMSO concentrations, which were set at $5 \%$ and $1 \%$, respectively. $\mathrm{PHH}$ were treated or not for 12 days with fatty acids and drugs using the same protocol as for HepaRG cells.

Nile Red Staining, Cellular Triglycerides, and Cytotoxicity Assays. The Nile red dye allows the staining of neutral lipids within cells. For Nile red staining, the cells were washed with warm phosphate-buffered saline (PBS), fixed with $4 \%$ paraformaldehyde for 20 minutes at room temperature, and then washed 3 times with cold PBS. After paraformaldehyde fixation, cells were incubated with $0.05 \mu \mathrm{g} / \mathrm{ml}$ Nile red in PBS for 30 minutes at room temperature and then washed once with PBS. Nuclei were labeled with $10 \mu \mathrm{g} / \mathrm{ml}$ Hoechst dye and cells were observed with an ImageXpress Micro Confocal High-Content Imaging System (Molecular Devices, Berkshire, UK). Triglycerides were measured with a colorimetric kit purchased from Biovision (Milpitas, CA), using the manufacturer's recommendations. 
Cytotoxicity was assessed by measuring cellular ATP levels using the CellTiter-Glo Luminescent Cell Viability assay purchased from Promega (Charbonnières, France), according to the manufacturer's instructions. Briefly, untreated and treated HepaRG cells were first incubated with the CellTiter-Glo reagent for 10 minutes at $37^{\circ} \mathrm{C}$. The cells were then transferred in an opaque-walled multiwell plate, and the luminescent signal was quantified using a POLARstar Omega microplate reader (BMG Labtech, Ortenberg, Germany). Results were expressed in comparison with untreated cells. Fifty and $10 \%$ inhibitory concentration $\left(\mathrm{IC}_{50}\right.$ and $\left.\mathrm{IC}_{10}\right)$ values were calculated with a four-parameter logistic regression using GraphPad Prism software 6.0 (GraphPad, San Diego, CA).

Determination of CYP2E1 and CYP3A4 Activities. Measurement of the activities of cytochrome P450 isoforms 2E1 and 3A4 (CYP2E1 and CYP3A4) was performed as described elsewhere (Michaut et al., 2016). Briefly, HepaRG cells were incubated for 6 and 2 hours in phenol red-free and DMSO-free Williams' E medium containing $300 \mu \mathrm{M}$ chlorzoxazone or $200 \mu \mathrm{M}$ testosterone, respectively. At the end of the incubation, the cell culture media were collected and stored at $-80^{\circ} \mathrm{C}$ until analysis. We then quantified 6-hydroxychlorzoxazone by high-performance liquid chromatography with tandem mass spectrometry (Xenoblis, Rennes, France), whereas $6 \beta$-hydroxytestosterone was measured by high-performance liquid chromatography analysis.

Assessment of mtDNA Levels. Total DNA was extracted from about $3 \times 10^{5}$ HepaRG cells using a Blood and Cell Culture DNA Mini Kit (Qiagen, Les Ulis, France). The relative content of mtDNA was then assessed by real-time quantitative PCR analysis (RTqPCR) using the SYBR Green PCR Master Mix (Applied Biosystems, Woolston, United Kingdom) and an Applied Biosystems 7900HT Fast Real-Time PCR System (Applied Biosystems). The primers used to amplify a portion of the mtDNA gene encoding the cytochrome $c$ oxidase subunit 1 (MT-CO1, also referred to as COX1) were 5'-TACGTTGTAGCCCACTTCCACT-3' (forward) and 5'AGTAACGTCGGGGCATTCCG-3' (reverse). For normalization of mtDNA content, a portion of the nuclear DNA (nDNA) gene encoding the ribosomal protein S6 (RPS6) was amplified by using the following primers 5'-TGATGTCCGCCAGTATGTTG-3' (forward) and 5' TCTTGGTACGCTGCTTCTTC-3' (reverse). The $2^{-\Delta \Delta \mathrm{Ct}}$ method was then used to assess the relative mtDNA levels.

Isolation of RNA and Measurement of Gene Expression. Total RNA was extracted from about $6 \times 10^{5}$ HepaRG cells with the Nucleospin RNA isolation system purchased from Macherey-Nagel (Hoerdt, France), which included a DNase treatment step. RNAs were reverse-transcribed into cDNAs using the High-Capacity cDNA Reverse Transcription Kit purchased from Applied Biosystems. RT-qPCR was then performed as mentioned earlier. Expression of GAPDH was used as reference, and the $2^{-\Delta \Delta \mathrm{Ct}}$ method was used to express the relative expression of each selected gene. The sequences of the primers used to measure gene expression are presented in the Table 1.

Western Blot Analysis. At the end of the treatments, the cells were harvested, washed twice with ice-cold PBS, and lysed in a radioimmunoprecipitation assay buffer $(150 \mathrm{mM} \mathrm{NaCl}, 50 \mathrm{mM}$ Tris$\mathrm{HCl}, \mathrm{pH} 7.4,0.25 \%$ sodium deoxycholate, $0.1 \%$ sodium dodecylsulfate, 1 mM EDTA, 1\% NP-40) supplemented with protease and phosphatase inhibitors. We then separated $20 \mu \mathrm{g}$ of proteins by electrophoresis on NuPAGE 4\%-12\% gradient Bis-Tris gels (Thermo Fisher Scientific) and transferred them to $0.2-\mu \mathrm{m}$ nitrocellulose membranes (Bio-Rad Laboratories, Hercules, CA), which were saturated with $5 \%$ bovine serum albumin in Tris-buffered saline containing $0.1 \%$ Tween 20 for 2 hours at room temperature. Proteins were then immunoblotted with antibodies against $\mathrm{NADH}$ dehydrogenase subunit 1 (ND1), cytochrome $c$ oxidase subunits 2 and 4 (COX2 and COX4), mitochondrial ribosomal protein L11 (MRPL11), MRPL28, AMP-activated protein kinase $\alpha$-subunit (AMPK $\alpha$ ), phospho-AMPK $\alpha$ and $\beta$-actin, which was

TABLE 1

List of the primers used in this study

\begin{tabular}{|c|c|c|c|}
\hline Gene Symbol & Gene Name & Forward Primer & Reverse Primer \\
\hline APOA4 & Apolipoprotein A4 & CAGTGTGGCAAGAAACTCCT & GTAGTCCCACATCACCGTG \\
\hline$A C A D M$ & $\begin{array}{l}\text { Acyl-CoA dehydrogenase, C- } 4 \text { to C- } 12 \\
\text { straight chain }\end{array}$ & TTTGGGGAGAATGACTGAGG & TGGATCAGAACGTGCCAATA \\
\hline$A C O X 1$ & Acyl-CoA oxidase 1 & GATGAAGTATGCCCAGGTGAAG & CACAAGGAAGGACCTGACAAA \\
\hline COX4I1 & Cytochrome c oxidase subunit $4 \mathrm{I} 1$ & CAGAATGTTGGCTACCAGGG & GGTCACGCCGATCCATATAAG \\
\hline CPT1A & Carnitine palmitoyltransferase $1 \mathrm{~A}$ & CGGGAGGAAATCAAACCAATTC & CTGGGATCCGGGAAGTATTAAA \\
\hline CYP2E1 & $\begin{array}{l}\text { Cytochrome P450 family } 2 \text { subfamily } \\
\text { E member } 1\end{array}$ & TTGAAGCCTCTCGTTGACCC & CGTGGTGGGATACAGCAA \\
\hline СYР3А4 & $\begin{array}{l}\text { Cytochrome P450 family } 3 \text { subfamily } \\
\text { A member } 4\end{array}$ & CTTCATCCAATGGACTGCATAAAT & TCCCAAGTATAACACTCTACACAGACAA \\
\hline$G A P D H$ & $\begin{array}{l}\text { Glyceraldehyde-3-phosphate } \\
\text { dehydrogenase }\end{array}$ & ATGACATCAAGAAGGTGGTG & CATACCAGGAAATGAGCTTG \\
\hline HMOX1 & Heme oxygenase 1 & ACTTTCAGAAGGGCCAGGT & TTGTTGCGCTCAATCTCCT \\
\hline MT-CO2 & $\begin{array}{l}\text { Mitochondrially encoded cytochrome c } \\
\text { oxidase subunit II }\end{array}$ & CTGAACCTACGAGTACACCG & TTAATTCTAGGACGATGGGC \\
\hline$M T-N D 1$ & $\begin{array}{l}\text { Mitochondrially encoded NADH } \\
\text { dehydrogenase subunit } 1\end{array}$ & CCCTAAAACCCGCCACATCT & GAGCGATGGTGAGAGCTAAGGT \\
\hline NFE2L2 & Nuclear factor, erythroid 2 like 2 & TCAGCATGCTACGTGATGAAG & TTTGCTGCAGGGAGTATTCA \\
\hline$N Q O 1$ & $\mathrm{NAD}(\mathrm{P}) \mathrm{H}$ quinone dehydrogenase 1 & ACGTCCTTCAACTATGCCATG & TTACCTGTGATGTCCTTTCTGG \\
\hline$N R F 1$ & Nuclear respiratory factor 1 & GCCACAGCCACACATAGTATAG & CGTACCAACCTGGATAAGTGAG \\
\hline PLIN1 & Perilipin 1 & TGGTCCTCATGATCCTCCTC & GTTGTCGATGTCCCGGAATT \\
\hline PLIN2 & Perilipin 2 & CCATTCTACTGTTCACCTGATTGA & ACCCATGAGAGGTAGAGCTTAT \\
\hline$P O L G$ & DNA polymerase $\gamma$, catalytic subunit & GGCTGTCCAGGAAGAGTTTATG & CCACAAGCATGAGGTGTAAGT \\
\hline POLRMT & RNA polymerase mitochondrial & GGACTCCAAGGTCAAGCAAATA & TCTTCTGCTTACGTGTGTTGG \\
\hline PPARA & $\begin{array}{l}\text { Peroxisome proliferator activated } \\
\quad \text { receptor } \alpha\end{array}$ & GTTCTGGAAGCTTTGGCTTTAC & GAAAGCGTGTCCGTGATGA \\
\hline $\begin{array}{l}\text { PPARGC1A } \\
\text { (PGC1A) }\end{array}$ & PPARG coactivator $1 \alpha$ & AGTGGTGCAGTGACCAATCA & CTGCTAGCAAGTTTGCCTCA \\
\hline $\begin{array}{l}P P A R G C 1 B \\
\quad(P G C 1 B)\end{array}$ & PPARG coactivator $1 \beta$ & GTACATTCAAAATCTCTCCAGCGACATG & GAGGGCTCGTTCCTCAGGGCA \\
\hline SOD2 & Superoxide dismutase 2 & GGGTTGGCTTGGTTTCAATA & CTGATTTGGACAAGCAGCAA \\
\hline TFAM & Transcription factor A, mitochondrial & GCTCAGAACCCAGATGCAAA & TGCCACTCCGCCCTATAA \\
\hline TRIB3 & Tribbles pseudokinase 3 & CCCTGCTCACAGAGATGACA & GCAGCTGGTTTGTTTGTGAA \\
\hline
\end{tabular}


used as loading control. The dilution used for all antibodies was 1: 1000 except for those against COX2 and $\beta$-actin whose dilutions were 1:500 and 1:5000 respectively. Finally, the blots were incubated with appropriate secondary antibodies, and protein bands were revealed by enhanced chemiluminescence with the FusionFX7 Spectra system (Vilber Lourmat, Eberhardzell, Germany). COX4 and MRPL28 antibodies were purchased from Abcam (Cambridge, United Kingdom). AMPK $\alpha$, phospho-AMPK $\alpha$ (Thr172) and MRPL11 antibodies were purchased from Cell Signaling Technology (Danvers, MA). $\beta$-Actin antibodies were purchased from Santa Cruz Biotechnology. ND1 and COX2 antibodies were generated by the group of Dr. Anne Lombès, as previously reported elsewhere (Agier et al., 2012).

Measurement of Citrate Synthase Activity and Respiratory Chain Complex I Levels and Activity. Citrate synthase (CS) activity was measured with $20 \mu \mathrm{g}$ of proteins using the Citrate Synthase Assay Kit from Sigma-Aldrich, according to the manufacturer's recommendations. Complex I levels and activity were respectively measured with the Complex I Human Protein Quantity Dipstick Assay Kit and the Complex I Enzyme Activity Dipstick Assay kit purchased from Abcam, according to the manufacturer's instructions. In the assay, complex I is immunocaptured and immunoprecipitated in active form on the dipstick, which consists of a nitrocellulose membrane to which an anti-complex I monoclonal antibody is attached. Complex I levels and activity were measured immunochromatographically with $20 \mu \mathrm{g}$ of proteins using a Hamamatsu MS1000 Dipstick Reader (Abcam).

Measurement of Mitochondrial Respiration and Fatty Acid Oxidation. Mitochondrial respiration in the presence of L-glutamine $(2 \mathrm{mM})$, glucose $(10 \mathrm{mM})$, and pyruvate $(1 \mathrm{mM})$ was measured in adherent HepaRG cells using an Agilent Seahorse XFe24 Analyzer and the Mito Stress Test Kit (Agilent, Santa Clara, CA), according to the manufacturer's instructions. Oxygen consumption rates were normalized in each well by the number of cells estimated by the fluorescence intensity of the Hoechst dye $(10 \mu \mathrm{g} / \mathrm{ml})$. For some investigations, HepaRG cells were also cultured in Williams' E medium without glucose but supplemented with $11.1 \mathrm{mM}$ galactose. After 14 days, mitochondrial respiration was measured for each culture condition (i.e., glucose or galactose) in the presence of Lglutamine/pyruvate/glucose or L-glutamine/pyruvate/galactose with glucose and galactose at the same concentration (i.e., $10 \mathrm{mM}$ ).

These experiments showed that HepaRG cells cultured for 14 days with glucose or galactose presented similar basal and maximal (i.e., carbonyl cyanide $p$-trifluoromethoxyphenylhydrazone [FCCP]stimulated) mitochondrial respiration measured in the presence of glucose (Table 2). A trend toward lower maximal respiration was noticed when mitochondrial respiration was measured in the presence of galactose (Table 2). The ATP production parameter was similar between the different conditions (Table 2). Nonmitochondrial respiration and proton leak (two other parameters provided by the Mito Stress Test profile) were also unchanged between the four different conditions of mitochondrial assessment (data not shown).
Mitochondrial FAO was measured in adherent HepaRG cells using $\left[\mathrm{U}-{ }^{14} \mathrm{C}\right]$ palmitic acid $(0.05 \mu \mathrm{Ci} / \mathrm{ml})$, as previously described elsewhere (Anthérieu et al., 2011). The results for mitochondrial FAO were normalized to the total protein content determined by the bicinchoninic acid method.

Statistical Analysis. All results are expressed as mean \pm S.E.M. Comparisons between two groups were performed with a $t$ test. Comparisons between multiple groups were performed with twoway analysis of variance (ANOVA). When ANOVA provided statistically significant differences, the individual means were compared with the post hoc Bonferroni test. Statistical analyses were performed using GraphPad Prism software 6.0.

\section{Results}

Detection of Drug-Induced Alterations of mtDNA Homeostasis in HepaRG Cells. Zalcitabine and LNZ are known inhibitors of mtDNA replication and translation, respectively (Walker et al., 2004; De Vriese et al., 2006; Schon and Fromenty, 2015). In a first series of experiments, we verified that a 2 -week treatment with ddC and LNZ could induce these mitochondrial effects in differentiated HepaRG cells. A concentration of $20 \mu \mathrm{M}$ was used for each drug because our preliminary data showed no significant cytotoxicity that could interfere with the interpretation of the results. We found that ddC strongly reduced mtDNA levels, and this was associated with lower mRNA and protein expression of ND1 and COX2, two mtDNA-encoded polypeptides (Fig. 1, A-C). However, the expression of the nDNA-encoded COX4 was not decreased (Fig. 1C). Complex I levels were significantly reduced by ddC, but the activity of this complex was less affected $(P=0.15)$ (Fig. 1D).

Regarding LNZ, the 2-week treatment reduced the protein expression of ND1 and COX2, whereas COX4 protein expression, mtDNA levels, and mRNA expression of MT-ND1 and MT-CO2 were not decreased (Fig. 1, A-C). Complex I levels tended to be decreased $(P=0.06)$, while complex I activity was unaffected (Fig. 1D).

Finally, HepaRG cells were treated for 72 hours with ddC $(20 \mu \mathrm{M})$ and LNZ $(20 \mu \mathrm{M})$. No mtDNA depletion was observed with ddC, and the protein expression of ND1 and COX2 was not affected by LNZ (data not shown). Our 2-week treatment protocol was therefore appropriate to detect druginduced impairment of mtDNA replication and translation as well as the functional consequences of these deleterious effects.

Validation of the HepaRG Cell as a Model of NAFLD. In a recent study performed in HepaRG cells, we set up a

TABLE 2

Effects of glucose and galactose on mitochondrial function in HepaRG cells

HepaRG cells were cultured in a Williams' E medium with $11.1 \mathrm{mM}$ glucose or without glucose but supplemented with $11.1 \mathrm{mM}$ galactose. After 14 days, mitochondrial respiration was measured for each culture condition (i.e., glucose or galactose) in the presence of L-glutamine/pyruvate/glucose or L-glutamine/pyruvate/galactose with glucose and galactose at the same concentration $(10 \mathrm{mM})$. Three mitochondrial parameters (i.e., respiration rates in nanomoles per minute per $10^{6}$ cells) provided by the Mito Stress Test profile are shown. Results are mean \pm S.E.M. for three independent cultures.

\begin{tabular}{llccc}
\hline & \multirow{2}{*}{ Substrate for Culture } & $\begin{array}{c}\text { Substrate for } \\
\text { Respiration }\end{array}$ & \multicolumn{3}{c}{ Mito Stress Test Profile Parameters } \\
\cline { 3 - 5 } & & Basal Respiration & Maximal Respiration & ATP Production \\
\hline Glucose & Glucose & $3.7 \pm 0.2$ & $17.9 \pm 1.7$ & $2.8 \pm 0.3$ \\
Galactose & Glucose & $3.7 \pm 0.3$ & $17.5 \pm 2.0$ & $2.8 \pm 0.3$ \\
Glucose & Galactose & $3.6 \pm 0.2$ & $16.8 \pm 2.1$ & $2.8 \pm 0.2$ \\
Galactose & Galactose & $3.8 \pm 0.2$ & $15.0 \pm 1.7$ & $2.9 \pm 0.1$ \\
\hline
\end{tabular}




\section{Zalcitabine (ddC)}

A

\section{mtDNA levels}

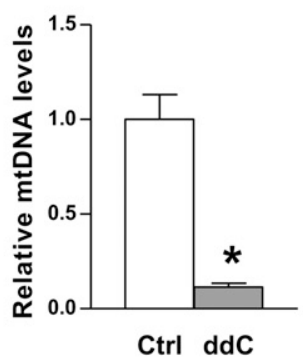

\section{B mRNA expression}

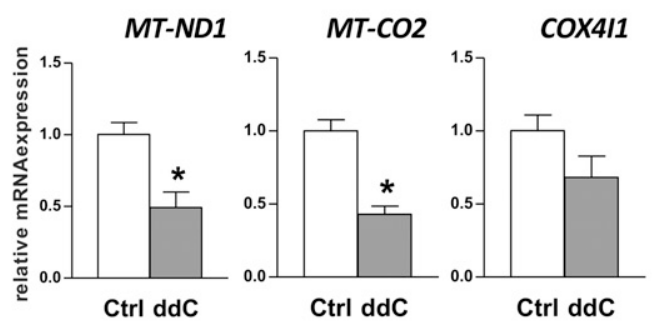

\section{Protein expression}

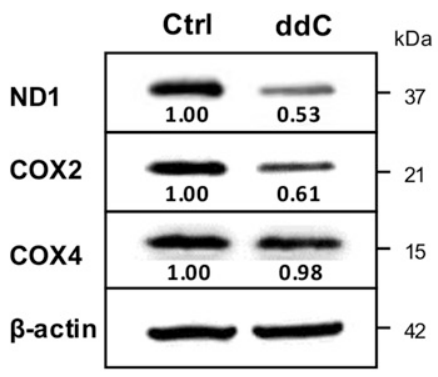

D

\section{Complex I levels and activity}

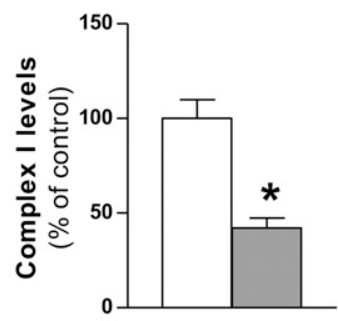

Ctrl ddC

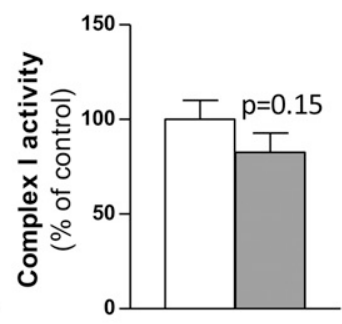

Ctrl ddC
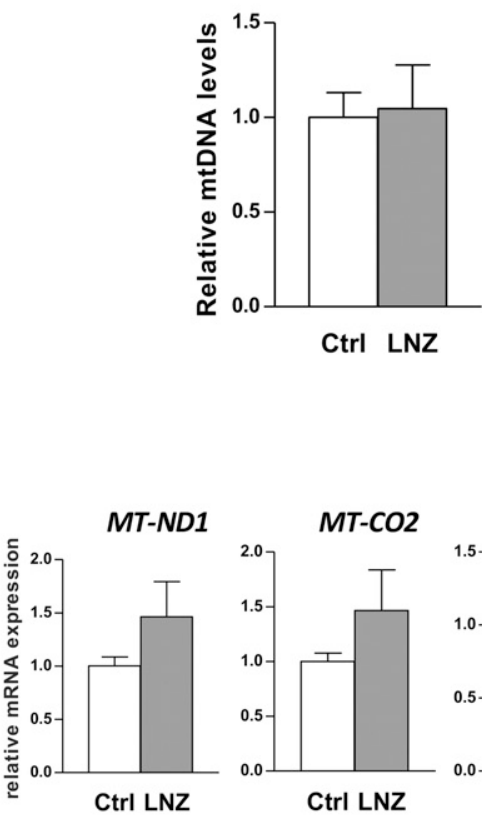

Linezolid (LNZ)

Ctrl LNZ
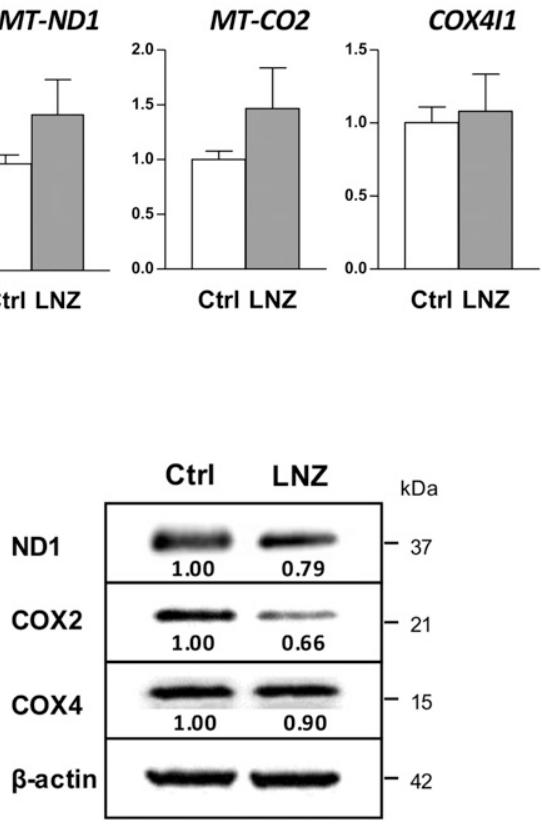

Fig. 1. Mitochondrial effects of zalcitabine (left) and linezolid (right). Nonsteatotic HepaRG cells were untreated (Ctrl) or treated with $20 \mu \mathrm{M}$ zalcitabine (ddC) or $20 \mu \mathrm{M}$ linezolid (LNZ) for 2 weeks, and several mitochondrial parameters were measured at the end of the treatment. (A) mtDNA levels. (B) mRNA expression of MT-ND1, MT-CO2 and COX4I1. (C) Protein expression of ND1, COX2, COX4, and $\beta$-actin. Numbers below the bands indicate the mean of the relative intensities for three independent cultures. (D) Complex I levels and activity. Results are mean \pm S.E.M. for three independent cultures (D) or five independent cultures (A and B). Statistical analysis was performed with a $t$ test. *Significantly different from untreated HepaRG cells.

model to study drug-induced hepatotoxicity in the context of NAFLD (Michaut et al., 2016). One rationale of that study was to find optimal conditions of HepaRG cell culture and fatty acid incubation to induce higher
CYP2E1 activity and lower CYP3A4 activity, which are both consistent alterations reported in NAFLD patients (Aubert et al., 2011; Woolsey et al., 2015; Michaut et al., 2016). 


\section{A Lipid accumulation}

Triglycerides

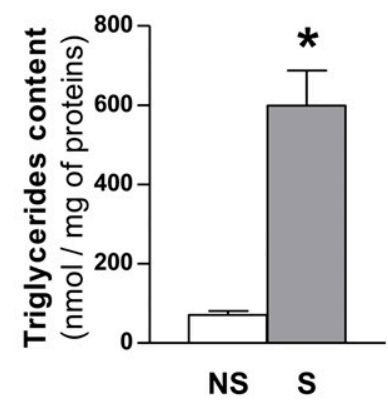

B

\section{mRNA expression}
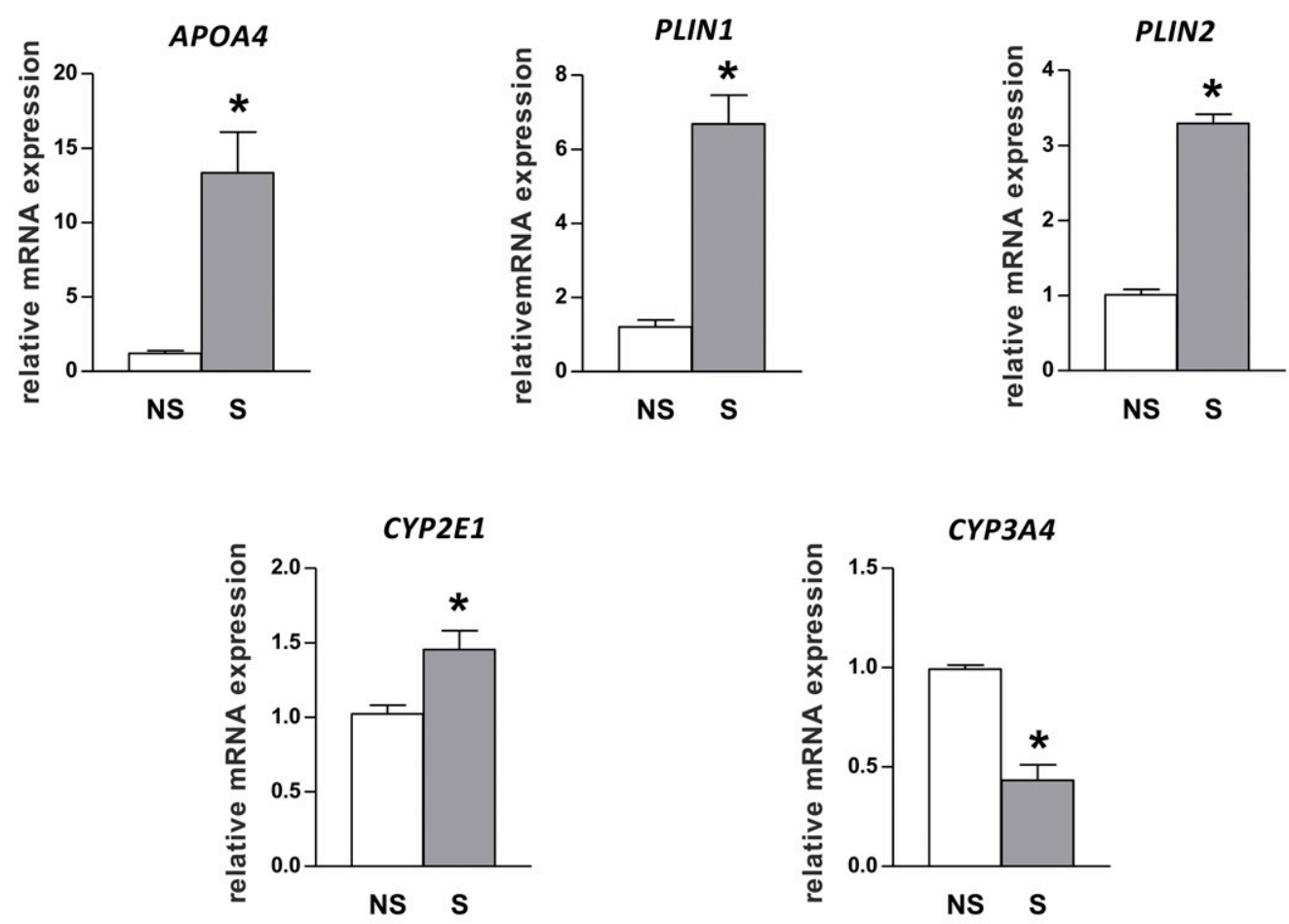

C

\section{CYP activity}
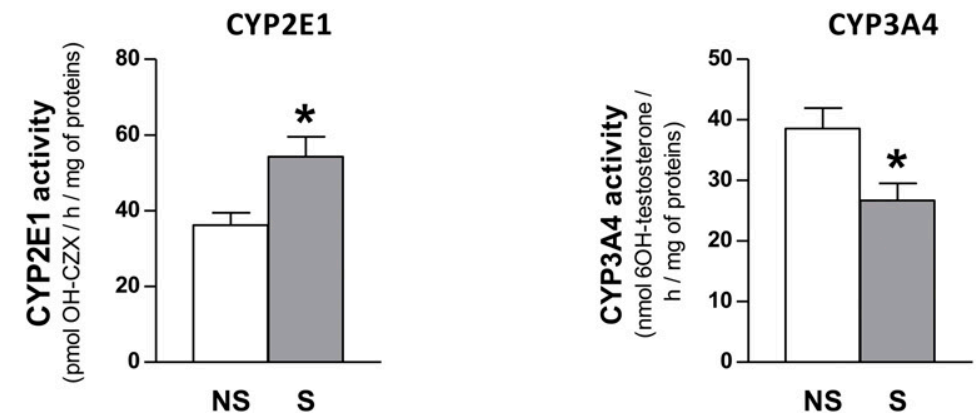

Fig. 2. Main features of the in vitro HepaRG cell model of steatosis induced by lipid overload. To induce steatosis, HepaRG cells were treated for 2 weeks with a mixture of stearic acid $(150 \mu \mathrm{M})$ and oleic acid $(150 \mu \mathrm{M})$. Nonsteatotic (NS) and steatotic (S) cells were then compared for different parameters linked to steatosis. (A) Lipid accumulation as assessed by levels of cellular triglycerides and neutral lipids (Nile red staining). (B) mRNA expression of APOA4, PLIN1, PLIN2, CYP2E1, and CYP3A4. (C) Activity of CYP2E1 and CYP3A4. Results are mean \pm S.E.M. for five independent cultures. Statistical analysis was performed with a $t$ test. *Significantly different from NS HepaRG cells. 
Higher CYP2E1 activity and lower CYP3A4 activity were obtained in HepaRG cells incubated for 1 week with stearic acid (Michaut et al., 2016). However, incubation of the HepaRG cells with stearic acid for 2 weeks induced significant toxicity ( $\sim 15 \%$ decrease in cellular ATP levels), leading to modification of the protocol.

After testing several conditions of fatty acid incubation, we found that a 2 -week treatment with a mixture of stearic acid $(150 \mu \mathrm{M})$ and oleic acid $(150 \mu \mathrm{M})$ did not cause significant cytotoxicity (data not shown) and gave satisfying results regarding cellular accumulation of neutral lipids including triglycerides (Fig. 2A) and mRNA expression of the lipid biomarkers apolipoprotein A4 (APOA4), perilipin 1 (PLIN1), and perilipin 2 (PLIN2, also known as ADFP) (Fig. 2B). Furthermore, CYP2E1 mRNA expression and activity were increased while CYP3A4 mRNA expression and activity were decreased (Fig. 2, B and C). Thus, this protocol of fatty acid treatment was selected for the present study.

Drug-Induced Cytotoxicity in Nonsteatotic and Steatotic Cells. One major goal of this study was to determine whether mtDNA homeostasis could be affected in nonsteatotic and steatotic HepaRG cells by different drugs, namely amiodarone, atorvastatin, carbamazepine, imipramine, lovastatin, perhexiline, ritonavir, terbinafine, and troglitazone. To this end, preliminary investigations were performed to assess the cytotoxic potential of each drug to select noncytotoxic drug concentrations for further studies on mtDNA homeostasis. Hence, cytotoxicity was determined by treating HepaRG cells with increasing concentrations of each drug, and $\mathrm{IC}_{50}$ and $\mathrm{IC}_{10}$ values were calculated for both nonsteatotic and steatotic cells.

$\mathrm{IC}_{50}$ could be calculated for all drugs except for terbinafine and carbamazepine because these drugs did not induce cytotoxicity in the range of concentrations that could be tested owing to their solubility in the culture medium (Table 3). The lack of carbamazepine and terbinafine cytotoxicity in HepaRG cells was somehow surprising because both drugs induced mitochondrial dysfunction for relatively low concentrations $(<100 \mu \mathrm{M})$ in isolated mouse liver mitochondria (Porceddu et al., 2012).

For amiodarone, atorvastatin, imipramine, lovastatin, and perhexiline, the $\mathrm{IC}_{50}$ and $\mathrm{IC}_{10}$ values were similar between nonsteatotic and steatotic HepaRG cells (Table 3). For troglitazone, the $\mathrm{IC}_{50}$ and $\mathrm{IC}_{10}$ were moderately but significantly lower in steatotic cells (Table 3), thus indicating higher cytotoxicity in the context of lipid accumulation. The converse profile was observed with ritonavir with lower cytotoxicity in steatotic HepaRG cells (Table 3).

Selection of Drug Concentrations to Study mtDNA Homeostasis. For drugs with calculated $\mathrm{IC}_{10}$, the selected concentrations were close to the $\mathrm{IC}_{10}$ and $\mathrm{IC}_{10} / 5$ to perform investigations in conditions of slight cytotoxicity or no cytotoxicity, respectively. An exception was for atorvastatin to use the same concentration as lovastatin, which belongs to the same pharmacologic class. For carbamazepine and terbinafine, for which no $\mathrm{IC}_{10}$ could be determined, arbitrary concentrations were chosen. Hence, the working concentrations of the different drugs were as follows: 4 and $20 \mu \mathrm{M}$ for amiodarone, 1 and $5 \mu \mathrm{M}$ for atorvastatin and lovastatin, 10 and $300 \mu \mathrm{M}$ for carbamazepine, 12 and $60 \mu \mathrm{M}$ for imipramine, 6 and $30 \mu \mathrm{M}$ for perhexiline, 9 and $45 \mu \mathrm{M}$ for ritonavir, 10 and $100 \mu \mathrm{M}$ for terbinafine and 10 and $50 \mu \mathrm{M}$ for troglitazone.

Importantly, the highest working concentrations corresponded to about $6,8,24,25,47,83,100,107$ and $500 \times C_{\max }$ for ritonavir, troglitazone, amiodarone, terbinafine, carbamazepine, atorvastatin, imipramine, perhexiline, and lovastatin, respectively (Table 3 ). Thus, for all drugs except lovastatin, these concentrations were lower, equivalent, or slightly above than the $100 \times C_{\max }$ cutoff classically used for safety assessment in the pharmaceutic industry (Dykens et al., 2008; Porceddu et al., 2012). Lovastatin was kept in our study to compare its mitochondrial effects with atorvastatin, which belong to the same pharmacologic class.

Effects of the Nine Drugs on mtDNA Levels and Expression of ND1 and COX2 at the mRNA and Protein Levels. In a next series of investigations, we determined the effects of the nine drugs on mtDNA homeostasis in nonsteatotic and steatotic HepaRG cells. For this purpose, HepaRG cells were treated with each drug for 2 weeks to determine their respective effects on mtDNA levels and on the mRNA and protein expression of ND1 and COX2.

None of these drugs decreased mtDNA levels (Figs. 3A, 4A, and 5). Instead, mtDNA levels were significantly increased with amiodarone, carbamazepine, imipramine, terbinafine, and troglitazone, especially for their highest concentrations (Fig. 3A; Fig. 5). For amiodarone, carbamazepine, and troglitazone, increased mtDNA levels were particularly observed in

TABLE 3

Drug-induced cytotoxicity in nonsteatotic and steatotic HepaRG cells

Cytotoxicity was assessed by measuring cellular ATP levels and $\mathrm{IC}_{50}$ and $\mathrm{IC}_{10}$ values were subsequently calculated. Results are mean \pm S.E.M. for four independent cultures. Statistical analysis was performed with a $t$ test. $C_{\max }$ values are from Porceddu et al. (2012).

\begin{tabular}{lcccccc}
\hline \multirow{2}{*}{ Drugs } & \multicolumn{2}{c}{$\mathrm{IC}_{50}(\mu \mathrm{M})$} & & \multicolumn{2}{c}{$\mathrm{IC}_{10}(\mu \mathrm{M})$} & $C_{\max }(\mu \mathrm{M})$ \\
\cline { 2 - 3 } & Nonsteatotic & Steatotic & & Nonsteatotic & Steatotic & \\
\hline Amiodarone & $29.8 \pm 0.6$ & $34.2 \pm 0.6$ & & $24.6 \pm 0.7$ & $23.4 \pm 0.7$ & 0.81 \\
Atorvastatin & $19.3 \pm 0.5$ & $17.0 \pm 0.5$ & & $15.0 \pm 0.6$ & $11.0 \pm 0.6$ & 0.06 \\
Carbamazepine & $>300$ & $>300$ & & $>300$ & $>300$ & 6.43 \\
Imipramine & $79.8 \pm 0.5$ & $75.6 \pm 0.5$ & & $66.2 \pm 0.6$ & $63.0 \pm 0.6$ & 0.6 \\
Lovastatin & $13.8 \pm 0.6$ & $10.8 \pm 0.6$ & & $6.5 \pm 0.7$ & $4.0 \pm 0.6$ & 0.01 \\
Perhexiline & $32.4 \pm 1.8$ & $33.0 \pm 0.7$ & & $30.7 \pm 0.8$ & $30.6 \pm 0.6$ & 0.28 \\
Ritonavir & $51.3 \pm 0.5$ & $58.8 \pm 0.6^{a}$ & & $43.8 \pm 0.6$ & $46.8 \pm 0.6$ & 7.07 \\
Terbinafine & $>100$ & $>100$ & & $>100$ & $>100$ & 4 \\
Troglitazone & $70.4 \pm 0.5$ & $58.6 \pm 0.6^{a}$ & & $66.1 \pm 0.5$ & $51.1 \pm 0.7^{a}$ & 6.6 \\
\hline
\end{tabular}

${ }^{a}$ Statistically significantly different from nonsteatotic HepaRG cells $(P<0.05)$. 


\section{A mtDNA levels}

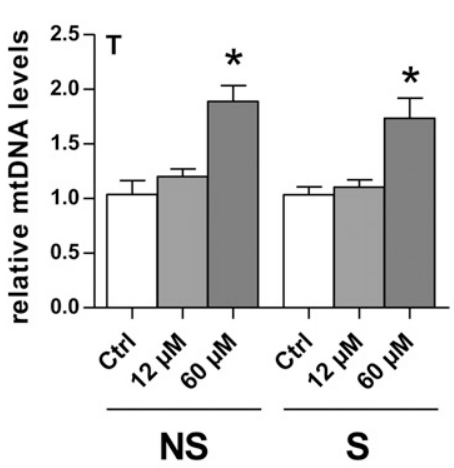

B

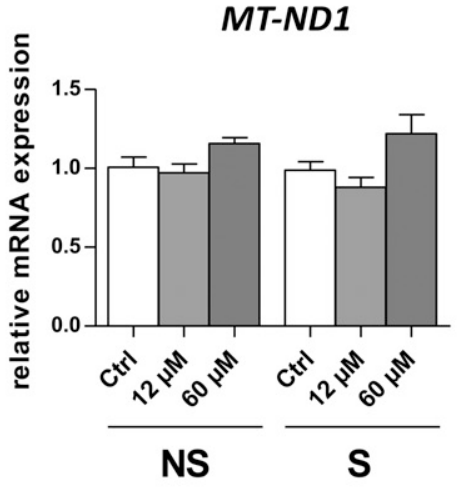

MT-CO2

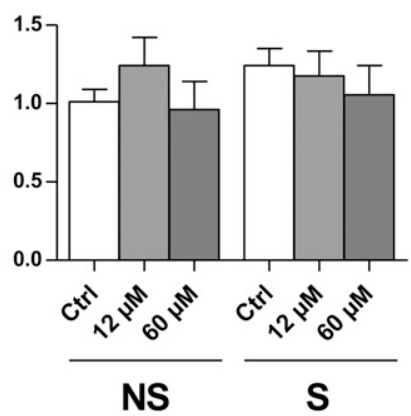

\section{Protein expression}

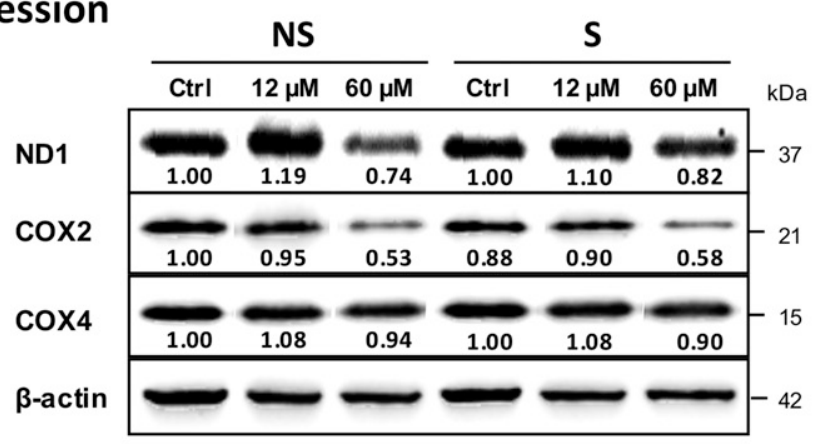

\section{Complex I levels}

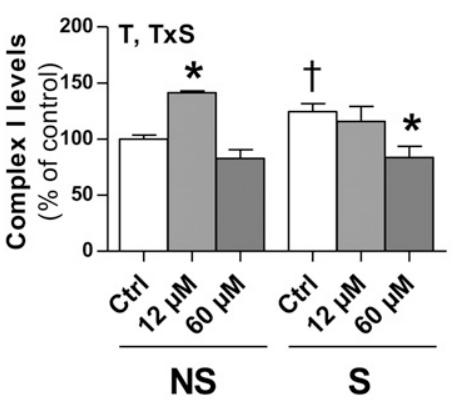

E Complex I activity

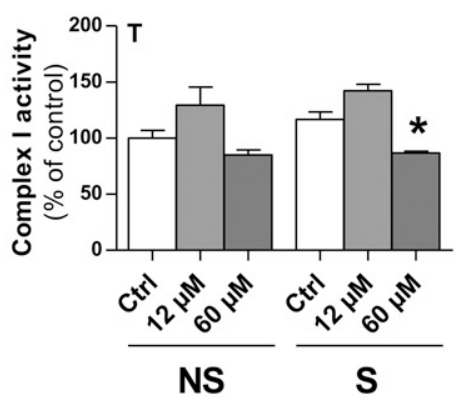

F CS activity

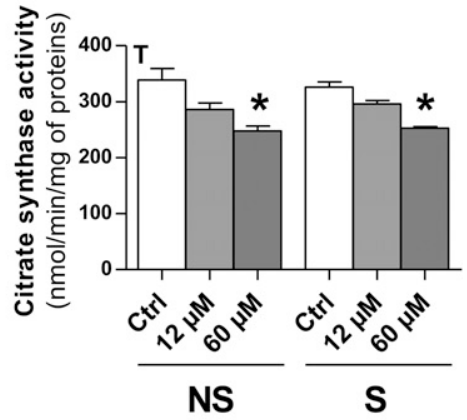

\section{G Mitochondrial respiration}

\section{Basal}

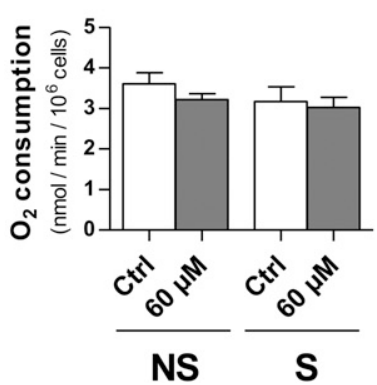

Maximal

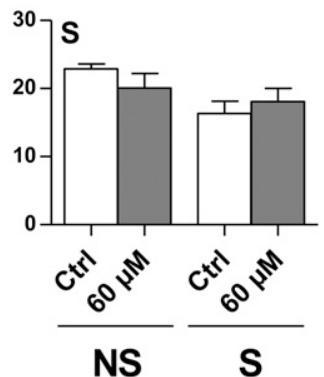

\section{H Palmitate oxidation}

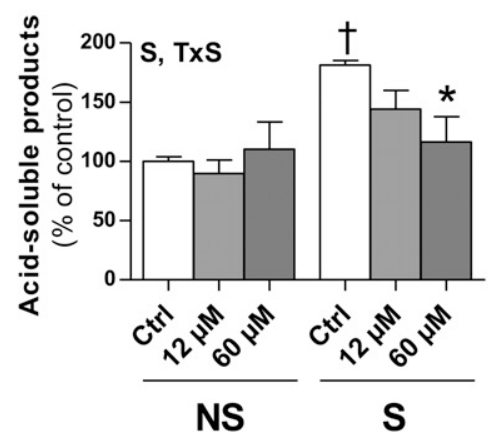

Fig. 3. Mitochondrial effects of imipramine. Nonsteatotic (NS) and steatotic (S) HepaRG cells were untreated (Ctrl) or treated with 12 or $60 \mu \mathrm{M}$ imipramine for 2 weeks, and several mitochondrial parameters were measured at the end of the treatment. (A) mtDNA levels. (B) mRNA expression of $M T-N D 1$ and MT-CO2. (C) Protein expression of ND1, COX2, COX4, and $\beta$-actin. Numbers below the bands indicate the mean of the relative intensities for three independent cultures. (D) Complex I levels. (E) Complex I activity (F) Citrate synthase (CS) activity. (G) Basal and maximal mitochondrial respiration. (H) Palmitate oxidation. Results are mean \pm S.E.M. for three independent cultures (D-F), four independent cultures (G and H), or six independent cultures (A). Statistical analysis was performed with a two-way ANOVA: T, effect of treatment, S, effect of steatosis, TxS, interaction between treatment and steatosis. Individual means were then compared with the post hoc Bonferroni test. *Significantly different from untreated NS or S cells. $\dagger$ Significantly different from NS cells $(P<0.05)$. 


\section{A mtDNA levels}

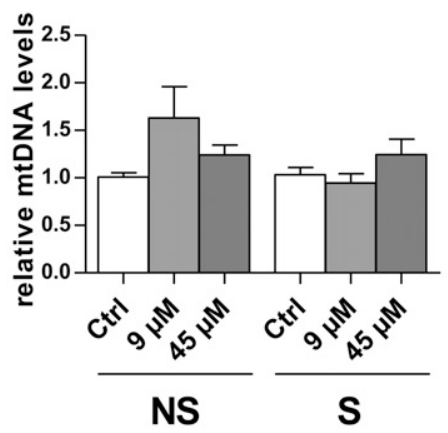

\section{B mRNA expression}

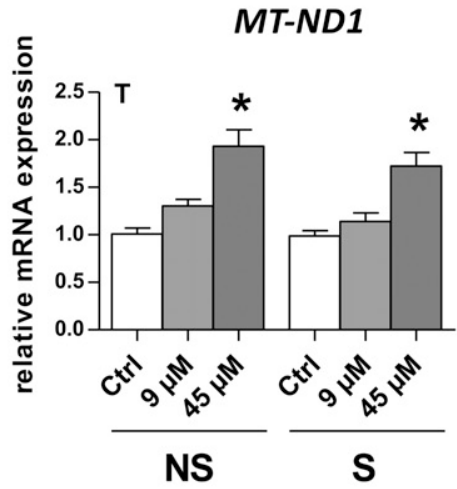

MT-CO2

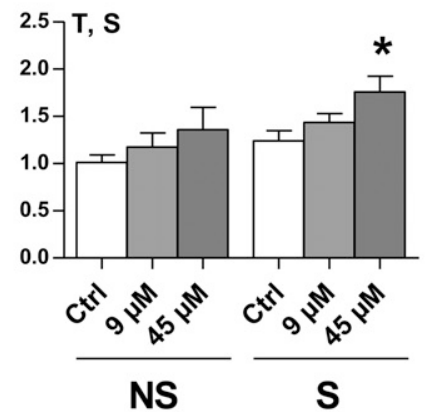

\section{Protein expression}

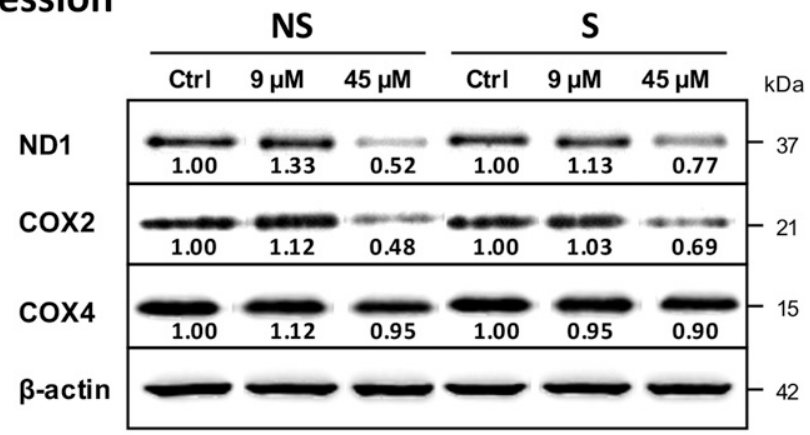

D Complex I levels

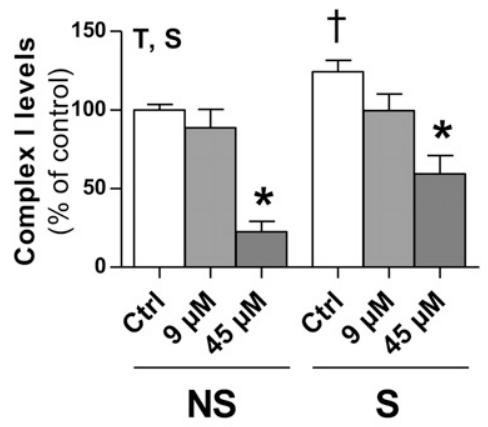

E Complex I activity

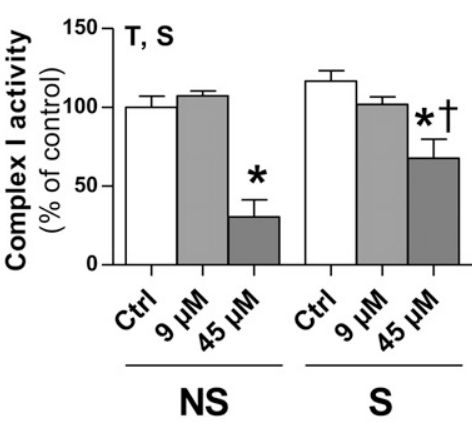

$\mathbf{F}$

\section{Basal}

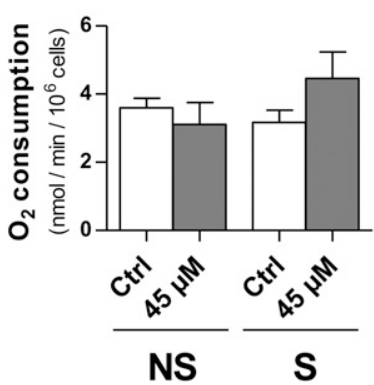

Maximal

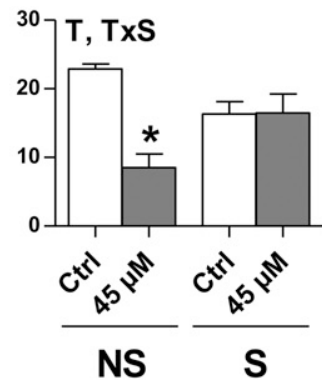

H

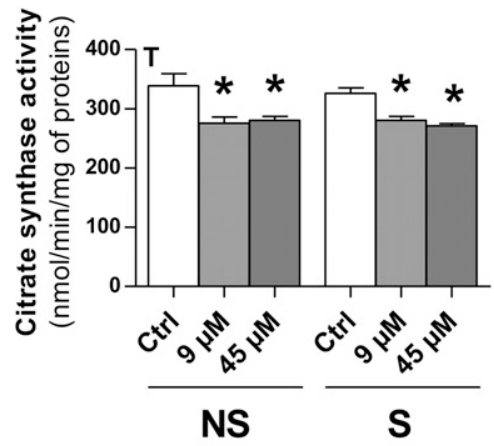

Palmitate oxidation

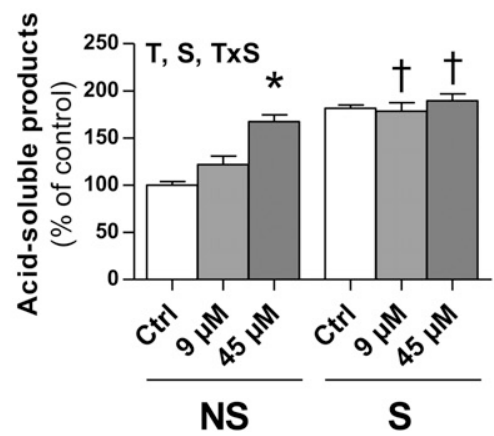

Fig. 4. Mitochondrial effects of ritonavir. Nonsteatotic (NS) and steatotic (S) HepaRG cells were untreated (Ctrl) or treated with 9 or $45 \mu \mathrm{M}$ ritonavir for 2 weeks, and several mitochondrial parameters were measured at the end of the treatment. (A) mtDNA levels. (B) mRNA expression of MT-ND1 and MT-CO2. (C) Protein expression of ND1, COX2, COX4, and $\beta$-actin. Numbers below the bands indicate the mean of the relative intensities for three independent cultures. (D) Complex I levels. (E) Complex I activity (F) Citrate synthase (CS) activity. (G) Basal and maximal mitochondrial respiration. (H) Palmitate oxidation. Results are mean \pm S.E.M. for three independent cultures (D-F), four independent cultures (B, G, and H), or six independent cultures (A). Statistical analysis was performed with a two-way ANOVA: T, effect of treatment, S, effect of steatosis, TxS, interaction between treatment and steatosis. Individual means were then compared with the post hoc Bonferroni test. *Significantly different from untreated NS or S cells. $\dagger$ Significantly different from NS cells treated by the same concentration of ritonavir $(P<0.05)$. 


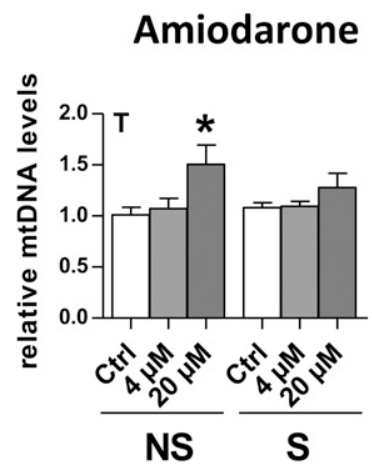

Lovastatin

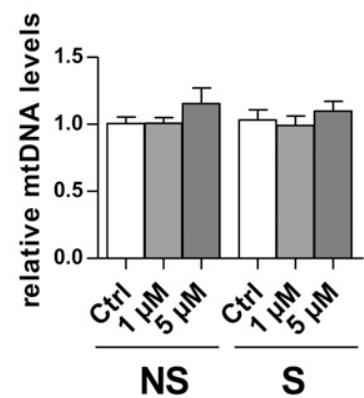

Atorvastatin

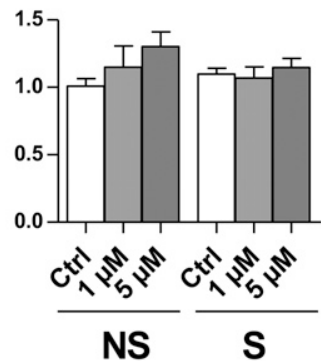

Perhexiline

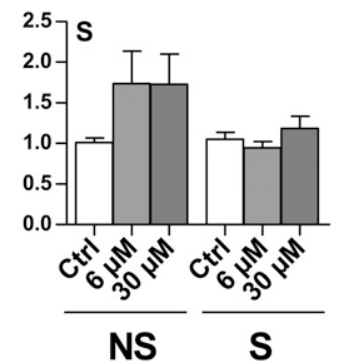

Carbamazepine

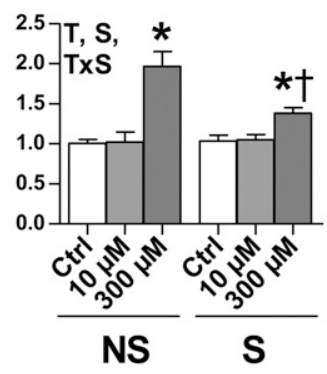

\section{Troglitazone}
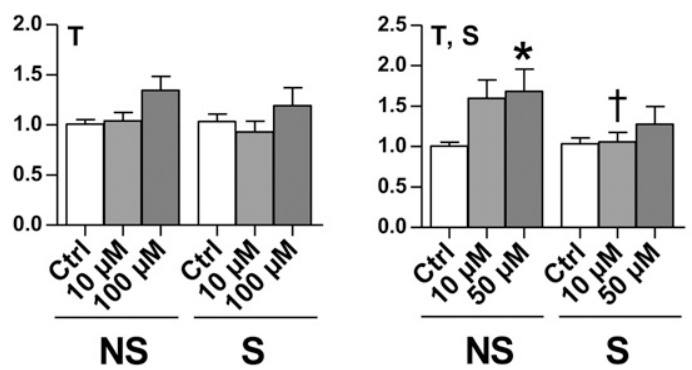

Fig. 5. Drug-induced modulation of mtDNA levels. Nonsteatotic (NS) and steatotic (S) HepaRG cells were untreated (Ctrl) or treated for 2 weeks with different concentrations of amiodarone, atorvastatin, carbamazepine, lovastatin, perhexiline, terbinafine, or troglitazone, and mtDNA levels were measured at the end of the treatment. Results are mean \pm S.E.M. for six independent cultures. Statistical analysis was performed with a two-way ANOVA: T, effect of treatment, $\mathrm{S}$, effect of steatosis, TxS, interaction between treatment and steatosis. Individual means were then compared with the post hoc Bonferroni test. *Significantly different from untreated NS or S cells. † Significantly different from NS cells treated by the same concentration of the drug $(P<0.05)$.

the absence of steatosis (Fig. 5). The mRNA expression of MT-ND1 and MT-CO2 was also enhanced by different drugs with the exceptions of imipramine, carbamazepine, and terbinafine (Fig. 3B; Fig. 4B; Table 4). Overall, there was no clear relationship between mtDNA levels and the mRNA expression of MT-ND1 and MT-CO2 (Figs. 3-5; Table 4). Six drugs also significantly increased the mRNA expression of COX4I1 (Table 4).

Next, the protein expression of ND1 and COX2 was investigated. The highest concentrations of imipramine and ritonavir reduced ND1 and COX2 protein levels (Fig. 3C; Fig. $4 \mathrm{C}$ ), whereas the other drugs did not alter the expression of these mtDNA-encoded proteins (data not shown). Ritonavirinduced reduction of ND1 and COX2 protein expression was apparently more pronounced in nonsteatotic HepaRG cells as compared with steatotic cells (Fig. 4C). Importantly, imipramine and ritonavir did not reduce COX4 protein levels (Fig. 3C; Fig. 4C). This result, together with the previously mentioned data, strongly suggested that imipramine and ritonavir impaired mtDNA translation without affecting mtDNA replication and transcription.

Nonsteatotic and steatotic HepaRG cells (two independent cultures) were also treated for 3 days with imipramine (12 and $60 \mu \mathrm{M}$ ) or ritonavir (9 and $45 \mu \mathrm{M}$ ). Imipramine did not reduce ND1 and COX2 protein levels. By contrast, the highest concentration of ritonavir induced about $50 \%$ reduction of ND1 protein expression in nonsteatotic HepaRG cells, whereas ND1 levels were unchanged in steatotic cells (data not shown).
COX2 and COX4 protein levels were not affected by $45 \mu \mathrm{M}$ ritonavir in nonsteatotic and steatotic cells. Taken together, our results suggested that ritonavir-induced impairment of mtDNA translation might occur earlier than with LNZ and imipramine.

Further investigations were also performed in nonsteatotic and steatotic $\mathrm{PHH}$ treated or not for 12 days with ritonavir $(45 \mu \mathrm{M})$ or imipramine $(60 \mu \mathrm{M})$. Four lots of $\mathrm{PHH}$ from different donors were used for these investigations. Our results indicated that ritonavir and imipramine reduced ND1 and COX2 expression in three different donors, although the effects were variable between these individuals (Fig. 6). However, these drugs presented no effect in another donor (data not shown). Ritonavir-induced reduction of ND1 expression was more marked in nonsteatotic $\mathrm{PHH}$ as compared with steatotic $\mathrm{PHH}$ (Fig. 6). Interestingly, this effect was also observed in HepaRG cells after 3 days (data not shown) and 2 weeks of ritonavir treatment (Fig. 4).

Effects of Imipramine and Ritonavir on the Expression of MRPL11 and MRPL28. Recent data indicated that some toxicants inducing mitochondrial stress could impair mitochondrial translation by reducing the levels of different mitochondrial ribosomal proteins including MRPL11 and MRPL28 (Quiros et al., 2017). Hence, we determined whether imipramine and ritonavir could reduce the levels of these proteins. However, MRPL11 and MRPL28 protein levels were not decreased with either drug after 2 weeks of treatment (data not shown). No change was also observed with $20 \mu \mathrm{M}$ LNZ (data not shown). 


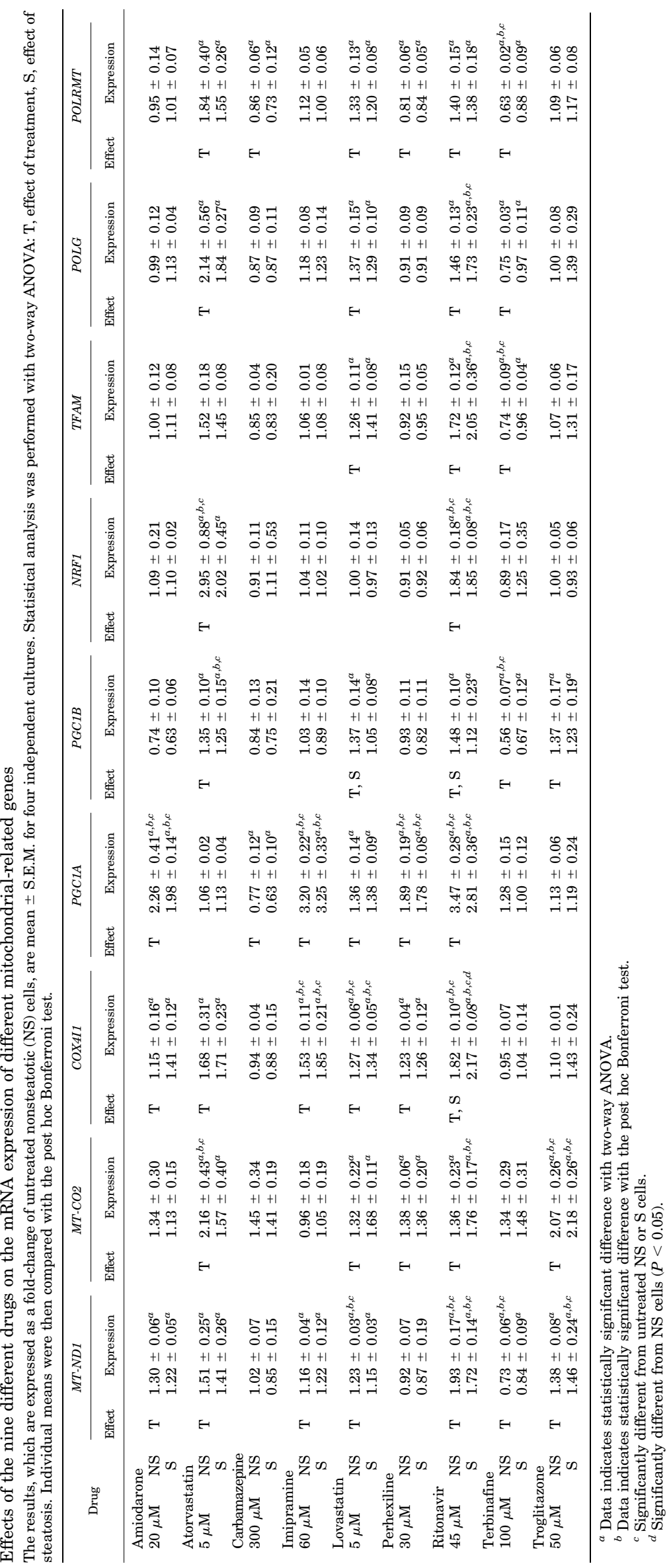




\section{Donor 1}

A

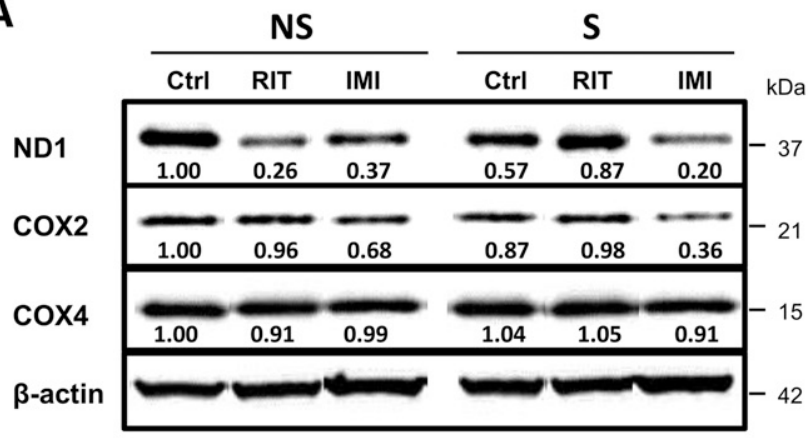

\section{Donor 2}

B

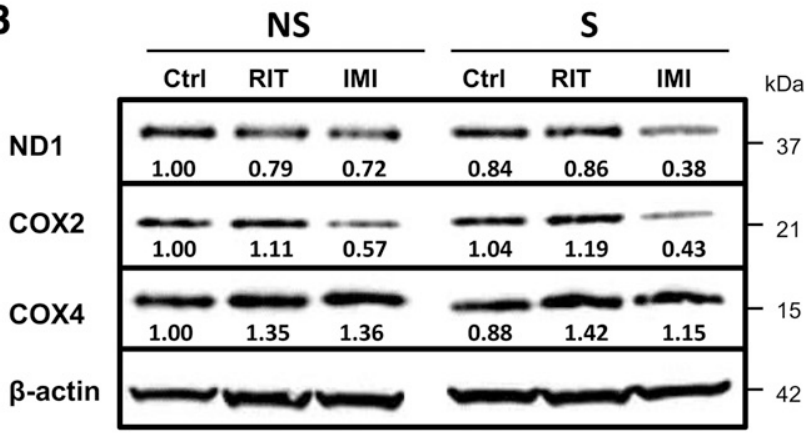

\section{Donor 3}

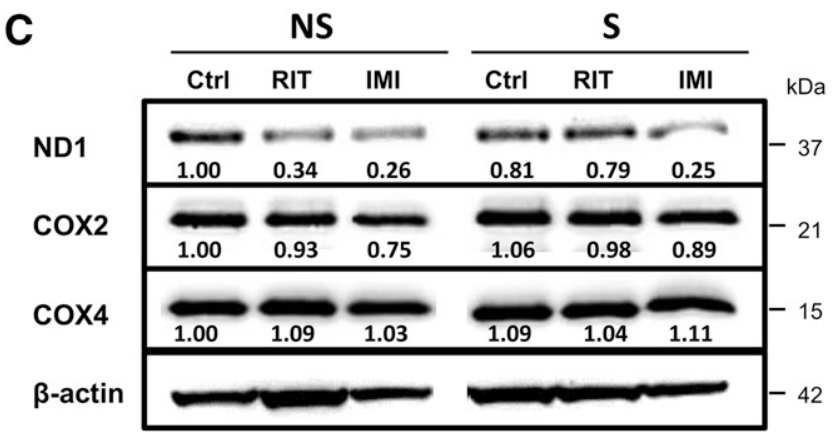

Fig. 6. Effect of imipramine and ritonavir on ND1, COX2, and COX4 expression in primary human hepatocytes. Nonsteatotic (NS) and steatotic (S) primary human hepatocytes $(\mathrm{PHH})$ from three different donors $(\mathrm{A}-\mathrm{C})$ were untreated $(\mathrm{Ctrl})$ or treated with $45 \mu \mathrm{M}$ ritonavir $(\mathrm{RIT})$ or $60 \mu \mathrm{M}$ imipramine (IMI) for 12 days, and protein expression of ND1, COX2, and COX 4 was assessed at the end of the treatments. $\beta$-Actin was used as loading control.

Effects of Imipramine and Ritonavir on Complex I Levels and Activity, CS Activity, Mitochondrial Respiration, and Fatty Acid Oxidation. To determine whether imipramine and ritonavir-induced reduction of mtDNAencoded protein levels could have functional consequences, the complex I levels and activity were first measured at the end of the treatments. With imipramine $(60 \mu \mathrm{M})$, complex I levels and activity were particularly decreased in steatotic cells (Fig. 3, D and E), whereas ritonavir $(45 \mu \mathrm{M})$ induced a stronger reduction of these parameters in nonsteatotic cells (Fig. 4, D and E). When data collected with both imipramine and ritonavir were taken into account, a robust correlation $\left(R^{2}=0.89 ; P<0.001\right)$ was observed between complex I levels and complex I activity. Furthermore, a significant correlation existed between ND1 protein expression on the one hand, and complex I levels $\left(R^{2}=0.58 ; P=0.01\right)$ or complex I activity $\left(R^{2}=0.69 ; P<0.01\right)$ on the other hand. CS activity was also significantly decreased by imipramine (Fig. $3 \mathrm{~F}$ ) and ritonavir (Fig. $4 \mathrm{~F}$ ) in both nonsteatotic and steatotic cells.

Oxygen consumption was next assessed in adherent HepaRG cells. Imipramine $(60 \mu \mathrm{M})$ did not modify mitochondrial respiration (Fig. 3G), but ritonavir ( $45 \mu \mathrm{M}$ ) significantly reduced the maximal (i.e., FCCP-stimulated) respiration in nonsteatotic cells (Fig. 4G). Mitochondrial $\beta$-oxidation of palmitic acid was also specifically assessed in adherent HepaRG cells. Imipramine significantly reduced mitochondrial FAO, but only in steatotic HepaRG cells (Fig. 3H).

Surprisingly, ritonavir induced a significant increase in mitochondrial FAO, although this effect was observed only in nonsteatotic HepaRG cells (Fig. 4H). This effect in nonsteatotic cells was accompanied with a significantly higher mRNA expression of peroxisome proliferator-activated receptor- $\alpha$ $(\operatorname{PPAR} \alpha)$ and its target gene liver carnitine palmitoyltransferase 1 (CPT1A), whereas the expression of medium chain acylCoA dehydrogenase (ACADM) and peroxisomal acyl-coenzyme A oxidase (ACOX) was unchanged (data not shown).

Finally, it was noteworthy that basal mitochondrial FAO was higher in steatotic cells compared with nonsteatotic cells (Fig. 3H; Fig. 4H). This is consistent with several reports showing increased mitochondrial FAO in experimental and clinical NAFLD (Begriche et al., 2013; Sunny et al., 2017).

Effects of the Nine Drugs on the mRNA Expression of Key Factors Involved in Mitochondrial Biogenesis. In this study, several drugs (i.e., amiodarone, carbamazepine, imipramine, terbinafine, troglitazone) significantly enhanced mtDNA levels (Figs. 3A and 5). Thus, we next determined for all drugs the mRNA expression of four factors playing a key role in mitochondrial biogenesis, namely peroxisome proliferatoractivated receptor- $\gamma$ coactivator $1 \alpha$ and $1 \beta$ (PGC- $1 \alpha$ and PGC- $1 \beta$ ), nuclear respiratory factor 1 (NRF1), and mitochondrial transcription factor A (TFAM) (Scarpulla et al., 2012; Villena, 2015; Ploumi et al., 2017).

However, different profiles of expression of PGC1A, PGC1B, NRF1, and TFAM were observed among the drugs (Table 4), and there was no apparent relationship between these profiles and the ability of some of these drugs to increase mtDNA levels. An interesting observation was that basal PGC1B expression was significantly reduced by about $25 \%$ in steatotic HepaRG cells when compared with nonsteatotic HepaRG cells $(P<0.01)$ (data not shown).

Finally, the expression of POLG (DNA polymerase $\gamma$ ) and POLRMT (RNA polymerase mitochondrial) was determined because these polymerases play a key role in mitochondrial biogenesis and function (Scarpulla et al., 2012; Vega et al., 2015). Only ritonavir, atorvastatin, and lovastatin significantly increased the expression of both POLG and POLRMT, whereas carbamazepine and terbinafine reduced their expression (Table 4). No significant change was observed with the other drugs (Table 4).

Effects of the Nine Drugs on AMPK Activation. AMPK is another key factor in mitochondrial biogenesis and function, in particular by activating PGC1 $\alpha$ (Scarpulla et al., 2012; Vega et al., 2015; Ploumi et al., 2017). Thus, we 
determined whether the different drugs could activate AMPK by assessing the expression of phospho-AMPK $\alpha$. Activation of phospho-AMPK $\alpha$ was first validated after a 14-day treatment with A-769662 (Fig. 7).

Five drugs, namely amiodarone, imipramine, lovastatin, terbinafine, and troglitazone significantly increased phospho$\mathrm{AMPK} \alpha$ levels after a 14-day treatment at their highest concentrations (Fig. 7). However, for these drugs and A-769662, the phospho-AMPK $\alpha$ levels were not reduced in steatotic cells compared with the nonsteatotic cells (Fig. 7). Surprisingly, carbamazepine significantly reduced phosphoAMPK $\alpha$ levels compared with the untreated cells (Fig. 7).

Finally, we determined whether the expression of phosphoAMPK $\alpha$ levels observed in all conditions of treatment correlated with the corresponding mRNA expression of PGC1 $\alpha$. This correlation tended to be significant $(P=0.09)$ when phospho-AMPK $\alpha$ levels were taken into account but was highly significant $\left(R^{2}=0.52 ; P<0.001\right)$ when the phosphoAMPK $\alpha /$ total AMPK ratio was considered. In contrast, there was no correlation between phospho-AMPK $\alpha$ levels (or the phospho-AMPK $\alpha /$ total AMPK ratio) with mtDNA levels.

The moderate but significant increased phospho-AMPK $\alpha$ levels observed with $100 \mu \mathrm{M}$ terbinafine in steatotic cells was surprising because ATP levels were not reduced in this experimental condition (Table 3). Because oxidative stress can also activate AMPK (Horie et al., 2008; Morales-Alamo and Calbet, 2016), we determined whether terbinafine increased the expression of several oxidative stress-related genes, namely nuclear factor erythroid 2-like 2 (NFE2L2, sometimes referred to as Nrf2), heme oxygenase 1 (HMOX1), $\mathrm{NAD}(\mathrm{P}) \mathrm{H}$ quinone dehydrogenase 1 (NQO1), superoxide dismutase 2 (SOD2), and tribbles pseudokinase 3 (TRIB3). However, only HMOX1 and NQO1 expression was significantly increased by $100 \mu \mathrm{M}$ terbinafine, in particular in nonsteatotic cells (data not shown). Hence, energy shortage and oxidative stress were most probably not responsible for AMPK $\alpha$ activation in steatotic HepaRG cells treated with $100 \mu \mathrm{M}$ terbinafine.

\section{Discussion}

Drug-induced alteration of mtDNA homeostasis has been described only with a few drugs, especially with the antiretrovirals NRTIs and some antibiotics (Cohen, 2010; Schon and Fromenty, 2015). In this study, the respective inhibitory effects of ddC $(20 \mu \mathrm{M})$ and LNZ $(20 \mu \mathrm{M})$ on mtDNA replication and translation were observed in HepaRG cells after 2 weeks (Fig. 1) but not after 3 days (data not shown). This underlines the importance of an adequate duration of cell treatment to detect any significant drug-induced alterations of mtDNA homeostasis and their functional consequences.

Such delayed appearance of mitochondrial dysfunction is due to the existence of several threshold effects at different mitochondrial levels (Rossignol et al., 1999, 2003). In patients, mitochondrial toxicity and liver injury induced by NRTIs and LNZ usually occur after several weeks or months of treatment (Spengler et al., 2002; Walker et al., 2004; De Vriese et al., 2006; De Bus et al., 2010). The maximal plasma concentrations $\left(C_{\max }\right)$ of ddC in patients can be up to $1 \mu \mathrm{M}$ (Massarella et al., 1996). Thus, the concentration of ddC able to inhibit mtDNA replication in our cellular model represents $20 \times$ $C_{\text {max }}$. Regarding LNZ, (serum) $C_{\max }$ in patients can be up to $40 \mu \mathrm{M}$ (MacGowan, 2003), thus suggesting that the safety margin of this antibiotic is rather low.

Our data strongly suggest that the antidepressant drug imipramine and the antiretroviral protease inhibitor (PI) ritonavir specifically impede mitochondrial translation. Indeed, reduced ND1 and COX2 protein levels induced by imipramine $(60 \mu \mathrm{M})$ and ritonavir $(45 \mu \mathrm{M})$ were associated with neither lower expression of the corresponding mtDNA-

\section{A Expression of AMPK $\alpha$ and phospho-AMPK $\alpha$}

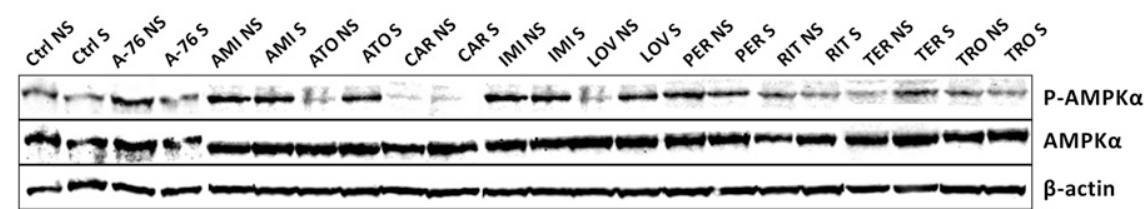

B

Phospho-AMPK $\alpha$ levels

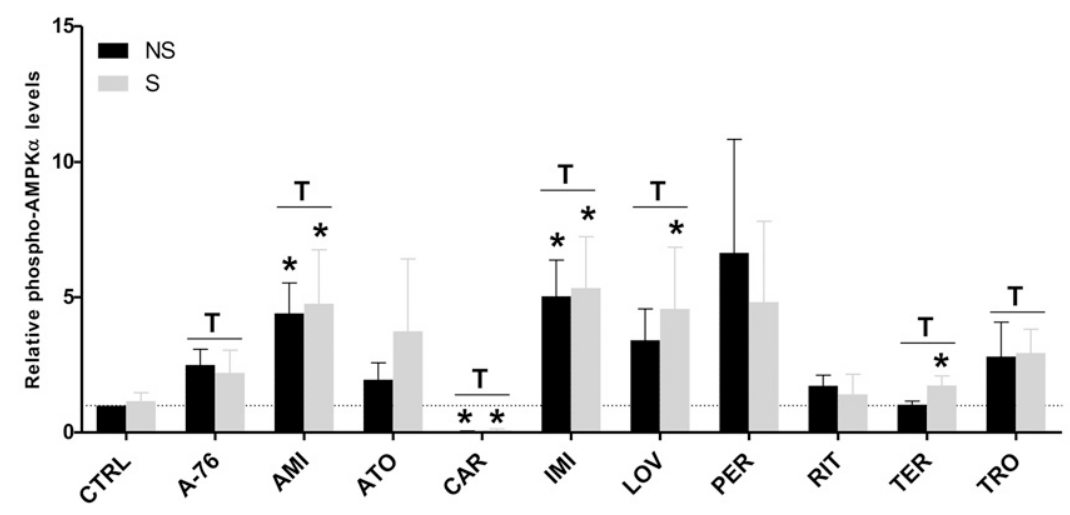

Fig. 7. Drug-induced AMPK activation. Nonsteatotic (NS) and steatotic (S) HepaRG cells were untreated (Ctrl) or treated for 2 weeks with $30 \mu \mathrm{M}$ A-769662 (A-76), $20 \mu \mathrm{M}$ amiodarone (AMI), $5 \mu \mathrm{M}$ atorvastatin (ATO), $300 \mu \mathrm{M}$ carbamazepine (CAR), $60 \mu \mathrm{M}$ imipramine (IMI), $5 \mu \mathrm{M}$ lovastatin (LOV), $30 \mu \mathrm{M}$ perhexiline (PER), $45 \mu \mathrm{M}$ ritonavir (RIT), $100 \mu \mathrm{M}$ terbinafine (TER), or $50 \mu \mathrm{M}$ troglitazone (TRO), and levels of phospho-AMPK $\alpha$ (P-AMPK $\alpha$ ), total AMPK $\alpha(\mathrm{AMPK} \alpha)$, and $\beta$-actin were assessed at the end of the treatment. (A) Representative Western blots for the different groups of treatment. (B) Quantification of phospho-AMPK $\alpha$ levels. Results are mean \pm S.E.M. for three independent cultures. Statistical analysis between untreated cells and cells treated with each drug was performed with a two-way ANOVA: T, effect of treatment. Individual means were then compared with the post hoc Bonferroni test. *Significantly different from untreated NS or S cells $(P<0.05)$. 
encoded transcripts nor with mtDNA depletion (Figs. 3 and 4). Moreover, reduced ND1 and COX2 protein levels were not accompanied by lower protein expression of COX4 (Figs. 3 and 4), MRPL11, or MRPL28 (data not shown), which are nDNAencoded mitochondrial proteins. Actually, these results were unexpected because mtDNA translation is usually impaired by antibiotics (Cohen, 2010; Schon and Fromenty, 2015). Further investigations will be required to determine whether imipramine and ritonavir could interact with the mitochondrial ribosomes, as shown for the antibiotics chloramphenicol, LNZ, and tetracycline (De Vriese et al., 2006; Cohen, 2010; Moullan et al., 2015).

Imipramine and ritonavir also reduced ND1 and COX2 protein expression in $\mathrm{PHH}$ from three different donors, although the effects were variable among these individuals (Fig. 6). This suggests the existence of an interindividual variability regarding imipramine and ritonavir-induced impairment of mitochondrial translation. Interestingly, genetic susceptibility was reported for antibiotic-induced alterations of mitochondrial protein synthesis and related adverse effects (Hobbie et al., 2008; Garrabou et al., 2017).

Originally developed as an antiretroviral PI, ritonavir is nowadays exclusively used in HIV-positive patients as a pharmacologic booster of other PIs. Indeed, by strongly inhibiting CYP3A4, ritonavir increases the bioavailability and plasma concentrations of other PIs (Hull and Montaner, 2011). However, although ritonavir is a CYP3A4 inhibitor, the bioactivation of ritonavir into several metabolites is dependent of this CYP in rodent and human (Kumar et al., 1996; Li et al., 2011). In the mouse, 26 different metabolites have been detected after ritonavir administration (Kumar et al., 1996), thus underlining the complexity of ritonavir metabolism.

In this study, ritonavir-induced cytotoxicity $\left(\mathrm{IC}_{50}\right)$ (Table 1) and impairment of complex I levels and activity (Fig. 4, D and E) were significantly lower in steatotic HepaRG cells. Notably, although basal CYP3A4 activity was significantly reduced in untreated steatotic HepaRG cells (Fig. 2), the remaining CYP3A4 activity in cells treated for 2 weeks with $45 \mu \mathrm{M}$ ritonavir was extremely low (maximum 8\%) and equivalent between nonsteatotic and steatotic cells (data not shown). Hence, CYP3A4 was probably not responsible for the lower ritonavir toxicity associated with steatosis. Further investigations would be needed to determine why ritonavir is less toxic in steatotic HepaRG cells.

Contrary to ritonavir, the antidiabetic drug troglitazone induced significantly higher cytotoxicity in steatotic HepaRG cells (Table 3). Moreover, the troglitazone-induced adaptive increase in mtDNA levels observed in nonsteatotic HepaRG cells was absent in steatotic cells. Importantly, troglitazone can be toxic by itself, in particular by directly impairing mitochondrial function (Nadanaciva et al., 2007; Porceddu et al., 2012). Although troglitazone can be biotransformed into several reactive metabolites, especially via CYP3A4, different investigations have suggested that these metabolites are overall less toxic than troglitazone itself (Masubuchi, 2006; Yokoi, 2010; Hosomi et al., 2011). Hence, our data suggest that higher troglitazone cytotoxicity in steatotic HepaRG cells could be due to lower troglitazone biotransformation, including via the CYP3A4 pathway.

Troglitazone, the first marketed thiazolidinedione, was actually withdrawn from the market in 2000 because of the occurrence of numerous cases of severe liver failure in patients with type 2 diabetes (Isley, 2003; Labbe et al., 2008; Massart et al., 2017). Because type 2 diabetes most often occurs in obese individuals, troglitazone-induced severe hepatotoxicity might have been favored by preexisting fatty liver in these patients. Interestingly, several experimental investigations showed that rosiglitazone, a thiazolidinedione that is still marketed, was more hepatotoxic in obese mice (Garcia-Ruiz et al., 2007; Massart et al., 2017).

Another important observation in our study was that several of the investigated drugs increased mtDNA levels in HepaRG cells after a treatment of 2 weeks. However, mtDNA levels in treated cells were in general higher in nonsteatotic compared with steatotic cells. This pattern was particularly striking with amiodarone, carbamazepine, and troglitazone (Fig. 5). Because differences in mtDNA levels could have been explained by changes in mitochondrial biogenesis, we determined the mRNA expression of several factors playing a key role in this process, including PGC1A, PGC1B, NRF1, TFAM, and phospho-AMPK $\alpha$. Moreover, POLG expression was also assessed. However, our data could not explain why some drugs increased mtDNA levels in HepaRG cells and why steatosis was associated with lesser mtDNA levels in HepaRG cells treated with amiodarone, carbamazepine, or troglitazone. Further investigations will be needed to determine whether these effects could be secondary to changes in the activity of these factors, rather than lower mRNA expression. Alternatively, other key factors involved in mtDNA homeostasis might have played a role.

Among the different drugs, only ritonavir (45 $\mu \mathrm{M})$ significantly increased the mRNA expression of all the mitochondrial-related genes investigated in this study, in both nonsteatotic and steatotic HepaRG cells (Table 4). Moreover, this drug also enhanced $\operatorname{PPAR} \alpha$ and CPT1A mRNA expression (data not shown) and palmitate oxidation in nonsteatotic cells (Fig. 4G). In contrast, the mtDNA levels were unchanged, and CS activity was reduced by the treatment, thus suggesting that the ritonavir-induced mitochondrial adaptive response was incomplete. Whether the lack of AMPK $\alpha$ activation (Fig. 7) might have played a role in such incomplete response will require further investigations. Notably, CS activity is frequently used as a bona fide marker of mitochondrial content in different pathophysiological situations such as inherited mitochondrial diseases (Guillery et al., 2008) and exercise training (Bishop et al., 2014). Hence, lower CS activity could reflect reduced mitochondrial content in ritonavir-treated cells despite higher mRNA expression of different nDNA and mtDNA-encoded mitochondrial proteins. Alternatively, ritonavir might directly inhibit the activity of this mitochondrial enzyme.

Previous investigations in HepG2 cells reported that druginduced cytotoxicity could be different when these cells were cultured in the presence of glucose or galactose, which was reported to favor mitochondrial metabolism (Marroquin et al., 2007; Paech et al., 2017). In the present study, we showed that HepaRG cells cultured for 14 days with glucose or galactose presented similar mitochondrial respiration (Table 2), thus indicating that galactose was not able to augment mitochondrial metabolism in HepaRG cells. Importantly, recent investigations reported that mitochondrial function (e.g., respiration and complex II and IV activities) in differentiated HepaRG cells was close to $\mathrm{PHH}$ and significantly superior compared with HepG2 cells (Peyta et al., 2016; Porceddu et al., 
2018). Taken together, these data indicate that HepaRG cells present fully functional mitochondria and that their culture with galactose is not able to further enhance mitochondrial capacity.

Because drug-induced alteration of mtDNA translation might have been overlooked in the past, especially for drugs that are not antibiotics, we would recommend including studies on mtDNA translation to investigators who wish to better understand how some compounds can alter mitochondrial function. To do so, the HepaRG cell line is a suitable model because drug toxicity can be studied over 2 weeks (our present study) or longer (Anthérieu et al., 2012). Moreover, this cell line could be appropriate to study drug-induced modulation of mitochondrial biogenesis. Indeed, the expression of several major mitochondrial biogenesis factors (e.g., PGC-1 $\alpha$, PGC-1 $\beta$, phospho-AMPK $\alpha$ ) was significantly increased or decreased by several investigated drugs. Interestingly, there was a significant correlation between the PGC1 $\alpha$ mRNA expression and the phospho-AMPK $\alpha /$ total AMPK ratio in treated HepaRG cells. Despite these advantages, HepaRG cells present some limitations, as previously pointed out (Michaut et al., 2016; Bucher et al., 2017). For instance, this cell line derives from one female patient and thus does not allow identifying gender differences or genetic susceptibility. Supplementary investigations in $\mathrm{PHH}$ can help to tackle these issues.

\section{Acknowledgments}

The authors thank the Institut National de la Santé et de la Recherche Médicale (INSERM) for its constant support.

\section{Authorship Contributions}

Participated in research design: Labbe, Fromenty.

Conducted experiments: Le Guillou, Bucher.

Contributed new reagents or analytic tools: Lombès.

Performed data analysis: Le Guillou, Bucher, Begriche, Hoët.

Wrote or contributed to the writing of the manuscript: Le Guillou,

Begriche, Lombès, Fromenty.

\section{References}

Agier V, Oliviero P, Lainé J, L'Hermitte-Stead C, Girard S, Fillaut S, Jardel C, Bouillaud F, Bulteau AL, and Lombès A (2012) Defective mitochondrial fusion, altered respiratory function, and distorted cristae structure in skin fibroblasts with heterozygous OPA1 mutations. Biochim Biophys Acta 1822:1570-1580.

Anthérieu S, Chesné C, Li R, Guguen-Guillouzo C, and Guillouzo A (2012) Optimization of the HepaRG cell model for drug metabolism and toxicity studies. Toxicol In Vitro 26:1278-1285.

Anthérieu S, Rogue A, Fromenty B, Guillouzo A, and Robin M-A (2011) Induction of vesicular steatosis by amiodarone and tetracycline is associated with up-regulation of lipogenic genes in HepaRG cells. Hepatology 53:1895-1905.

Aubert J, Begriche K, Knockaert L, Robin MA, and Fromenty B (2011) Increased expression of cytochrome P450 2E1 in nonalcoholic fatty liver disease: mechanisms and pathophysiological role. Clin Res Hepatol Gastroenterol 35:630-637.

Begriche K, Massart J, Robin M-A, Bonnet F, and Fromenty B (2013) Mitochondrial adaptations and dysfunctions in nonalcoholic fatty liver disease. Hepatology 58: 1497-1507.

Begriche K, Massart J, Robin M-A, Borgne-Sanchez A, and Fromenty B (2011) Druginduced toxicity on mitochondria and lipid metabolism: mechanistic diversity and deleterious consequences for the liver. J Hepatol 54:773-794.

Bishop DJ, Granata C, and Eynon N (2014) Can we optimise the exercise training prescription to maximise improvements in mitochondria function and content? Biochim Biophys Acta 1840:1266-1275.

Bucher S, Jalili P, Le Guillou D, Begriche K, Rondel K, Martinais S, Zalko D, Corlu A Robin MA, and Fromenty B (2017) Bisphenol a induces steatosis in HepaRG cells using a model of perinatal exposure. Environ Toxicol 32:1024-1036.

Cohen BH (2010) Pharmacologic effects on mitochondrial function. Dev Disabil Res Rev 16:189-199.

De Bus L, Depuydt P, Libbrecht L, Vandekerckhove L, Nollet J, Benoit D, Vogelaers $\mathrm{D}$, and Van Vlierberghe $\mathrm{H}$ (2010) Severe drug-induced liver injury associated with prolonged use of linezolid. J Med Toxicol 6:322-326.

Deschamps D, DeBeco V, Fisch C, Fromenty B, Guillouzo A, and Pessayre D (1994) Inhibition by perhexiline of oxidative phosphorylation and the beta-oxidation of fatty acids: possible role in pseudoalcoholic liver lesions. Hepatology 19:948-961.
De Vriese AS, Coster RV, Smet J, Seneca S, Lovering A, Van Haute LL, Vanopdenbosch LJ, Martin J-J, Groote CC, Vandecasteele S, et al. (2006) Linezolidinduced inhibition of mitochondrial protein synthesis. Clin Infect Dis $\mathbf{4 2}$ 1111-1117.

Dykens JA, Jamieson JD, Marroquin LD, Nadanaciva S, Xu JJ, Dunn MC, Smith AR, and Will Y (2008) In vitro assessment of mitochondrial dysfunction and cytotoxicity of nefazodone, trazodone, and buspirone. Toxicol Sci 103:335-345.

Eakins J, Bauch C, Woodhouse H, Park B, Bevan S, Dilworth C, and Walker P (2016) A combined in vitro approach to improve the prediction of mitochondrial toxicants. Toxicol In Vitro 34:161-170.

Fromenty B (2013) Drug-induced liver injury in obesity. J Hepatol 58:824-826.

Fromenty B, Fisch C, Berson A, Letteron P, Larrey D, and Pessayre D (1990) Dual effect of amiodarone on mitochondrial respiration. Initial protonophoric uncoupling effect followed by inhibition of the respiratory chain at the levels of complex I and complex II. J Pharmacol Exp Ther 255:1377-1384.

García-Ruiz I, Rodríguez-Juan C, Díaz-Sanjuán T, Martínez MA, Muñoz-Yagüe T, and Solís-Herruzo JA (2007) Effects of rosiglitazone on the liver histology and mitochondrial function in ob/ob mice. Hepatology 46:414-423.

Garrabou G, Soriano À, Pinós T, Casanova-Mollà J, Pacheu-Grau D, Morén C, García-Arumí E, Morales M, Ruiz-Pesini E, Catalán-Garcia M, et al. (2017) Influence of mitochondrial genetics on the mitochondrial toxicity of linezolid in blood cells and skin nerve fibers. Antimicrob Agents Chemother 61:e00542-17.

Guillery O, Malka F, Frachon P, Milea D, Rojo M, and Lombès A (2008) Modulation of mitochondrial morphology by bioenergetics defects in primary human fibroblasts. Neuromuscul Disord 18:319-330.

Hobbie SN, Akshay S, Kalapala SK, Bruell CM, Shcherbakov D, and Böttger EC (2008) Genetic analysis of interactions with eukaryotic rRNA identify the mitoribosome as target in aminoglycoside ototoxicity. Proc Natl Acad Sci USA 105: $20888-20893$.

Horie T, Ono K, Nagao K, Nishi H, Kinoshita M, Kawamura T, Wada H, Shimatsu A, Kita T, and Hasegawa K (2008) Oxidative stress induces GLUT4 translocation by activation of PI3-K/Akt and dual AMPK kinase in cardiac myocytes. $J$ Cell Physiol 215:733-742.

Hosomi H, Fukami T, Iwamura A, Nakajima M, and Yokoi T (2011) Development of a highly sensitive cytotoxicity assay system for CYP3A4-mediated metabolic activation. Drug Metab Dispos 39:1388-1395.

Hull MW and Montaner JSG (2011) Ritonavir-boosted protease inhibitors in HIV therapy. Ann Med 43:375-388.

Igoudjil A, Begriche K, Pessayre D, and Fromenty B (2006) Mitochondrial, metabolic and genotoxic effects of antiretroviral nucleoside reverse-transcriptase inhibitors. Antiinfect Agents Med Chem 5:273-292.

Isley WL (2003) Hepatotoxicity of thiazolidinediones. Expert Opin Drug Saf 2 $581-586$

Kamalian L, Chadwick AE, Bayliss M, French NS, Monshouwer M, Snoeys J, and Park BK (2015) The utility of HepG2 cells to identify direct mitochondrial dysfunction in the absence of cell death. Toxicol In Vitro 29:732-740.

Kumar GN, Rodrigues AD, Buko AM, and Denissen JF (1996) Cytochrome P450 mediated metabolism of the HIV-1 protease inhibitor ritonavir (ABT-538) in human liver microsomes. J Pharmacol Exp Ther 277:423-431.

Labbe G, Pessayre D, and Fromenty B (2008) Drug-induced liver injury through mitochondrial dysfunction: mechanisms and detection during preclinical safety studies. Fundam Clin Pharmacol 22:335-353.

Li F, Lu J, and Ma X (2011) Metabolomic screening and identification of the bioactivation pathways of ritonavir. Chem Res Toxicol 24:2109-2114.

MacGowan AP (2003) Pharmacokinetic and pharmacodynamic profile of linezolid in healthy volunteers and patients with gram-positive infections. J Antimicrob Chemother $\mathbf{5 1}$ (Suppl 2):ii17-ii25.

Marroquin L, Swiss R, and Will Y (2014) Identifying compounds that induce opening of the mitochondrial permeability transition pore in isolated rat liver mitochondria. Curr Protoc Toxicol 60:25.4.1-25.4.17.

Marroquin LD, Hynes J, Dykens JA, Jamieson JD, and Will Y (2007) Circumventing the Crabtree effect: replacing media glucose with galactose increases susceptibility of HepG2 cells to mitochondrial toxicants. Toxicol Sci 97:539-547.

Massarella JW, Nazareno LA, Passe S, and Min B (1996) The effect of probenecid on the pharmacokinetics of zalcitabine in HIV-positive patients. Pharm Res 13: 449-452.

Massart J, Begriche K, Moreau C, and Fromenty B (2017) Role of nonalcoholic fatty liver disease as risk factor for drug-induced hepatotoxicity. J Clin Transl Res 3 (Suppl 1):212-232.

Masubuchi Y (2006) Metabolic and non-metabolic factors determining troglitazone hepatotoxicity: a review. Drug Metab Pharmacokinet 21:347-356.

Michaut A, Le Guillou D, Moreau C, Bucher S, McGill MR, Martinais S, Gicquel T, Morel I, Robin M-A, Jaeschke H, et al. (2016) A cellular model to study druginduced liver injury in nonalcoholic fatty liver disease: application to acetaminophen. Toxicol Appl Pharmacol 292:40-55.

Michaut A, Moreau C, Robin M-A, and Fromenty B (2014) Acetaminophen-induced liver injury in obesity and nonalcoholic fatty liver disease. Liver Int 34:e171-e179.

Morales-Alamo D and Calbet JAL (2016) AMPK signaling in skeletal muscle during exercise: role of reactive oxygen and nitrogen species. Free Radic Biol Med 98: $68-77$.

Moullan N, Mouchiroud L, Wang X, Ryu D, Williams EG, Mottis A, Jovaisaite V, Frochaux MV, Quiros PM, Deplancke B, et al. (2015) Tetracyclines disturb mitochondrial function across eukaryotic models: a call for caution in biomedical research. Cell Reports 10:1681-1691.

Nadanaciva S, Dykens JA, Bernal A, Capaldi RA, and Will Y (2007) Mitochondrial impairment by PPAR agonists and statins identified via immunocaptured OXPHOS complex activities and respiration. Toxicol Appl Pharmacol 223:277-287.

Paech F, Bouitbir J, and Krähenbühl S (2017) Hepatocellular toxicity associated with tyrosine kinase inhibitors: mitochondrial damage and inhibition of glycolysis. Front Pharmacol 8:367. 
Peyta L, Jarnouen K, Pinault M, Guimaraes C, Pais de Barros JP, Chevalier S, Dumas JF, Maillot F, Hatch GM, Loyer P, et al. (2016) Reduced cardiolipin content decreases respiratory chain capacities and increases ATP synthesis yield in the human HepaRG cells. Biochim Biophys Acta 1857:443-453.

Ploumi C, Daskalaki I, and Tavernarakis N (2017) Mitochondrial biogenesis and clearance: a balancing act. FEBS $J$ 284:183-195.

Porceddu M, Buron N, Roussel C, Labbe G, Fromenty B, and Borgne-Sanchez A (2012) Prediction of liver injury induced by chemicals in human with a multiparametric assay on isolated mouse liver mitochondria. Toxicol Sci 129: 332-345.

Porceddu M, Buron N, Rustin P, Fromenty B, and Borgne-Sanchez A (2018) In vitro assessment of mitochondrial toxicity to predict drug-induced liver injury, in DrugInduced Liver Toxicity (Chen M and Will Y, eds) pp 283-300, Springer, Berlin, Germany.

Quirós PM, Prado MA, Zamboni N, D’Amico D, Williams RW, Finley D, Gygi SP, and Auwerx J (2017) Multi-omics analysis identifies ATF4 as a key regulator of the mitochondrial stress response in mammals. J Cell Biol 216:2027-2045.

Rossignol R, Faustin B, Rocher C, Malgat M, Mazat J-P, and Letellier T (2003) Mitochondrial threshold effects. Biochem $J$ 370:751-762.

Rossignol R, Malgat M, Mazat J-P, and Letellier T (1999) Threshold effect and tissue specificity. Implication for mitochondrial cytopathies. $J$ Biol Chem 274: 33426-33432.

Scarpulla RC, Vega RB, and Kelly DP (2012) Transcriptional integration of mitochondrial biogenesis. Trends Endocrinol Metab 23:459-466.

Schon EA and Fromenty B (2015) Mitochondria in liver disease, in Mitochondria in Liver Disease (Kaplowitz N and Han D eds) pp 283-314, Taylor \& Francis, New York.
Spengler U, Lichterfeld M, and Rockstroh JK (2002) Antiretroviral drug toxicity-a challenge for the hepatologist? J Hepatol 36:283-294.

Sunny NE, Bril F, and Cusi K (2017) Mitochondrial adaptation in nonalcoholic fatty liver disease: novel mechanisms and treatment strategies. Trends Endocrinol Metab 28:250-260

Vega RB, Horton JL, and Kelly DP (2015) Maintaining ancient organelles: mitochondrial biogenesis and maturation. Circ Res 116:1820-1834.

Villena JA (2015) New insights into PGC-1 coactivators: redefining their role in the regulation of mitochondrial function and beyond. FEBS J 282:647-672.

Walker UA, Bäuerle J, Laguno M, Murillas J, Mauss S, Schmutz G, Setzer B, Miquel R, Gatell JM, and Mallolas J (2004) Depletion of mitochondrial DNA in liver under antiretroviral therapy with didanosine, stavudine, or zalcitabine. Hepatology 39 311-317.

Wallace DC, Fan W, and Procaccio V (2010) Mitochondrial energetics and therapeutics. Annu Rev Pathol 5:297-348.

Will Y and Dykens J (2014) Mitochondrial toxicity assessment in industry-a decade of technology development and insight. Expert Opin Drug Metab Toxicol 10: 1061-1067.

Woolsey SJ, Mansell SE, Kim RB, Tirona RG, and Beaton MD (2015) CYP3A activity and expression in nonalcoholic fatty liver disease. Drug Metab Dispos 43: $1484-1490$

Yokoi T (2010) Troglitazone. Handb Exp Pharmacol 196:419-435.

Address correspondence to: Dr. Bernard Fromenty, INSERM, UMR 1241 (NuMeCan Institute), Université de Rennes 1, 35000 Rennes, France. E-mail: bernard.fromenty@inserm.fr 